\title{
Laser Bead-on-Plate Welding and Overlap Seams for Increasing the Strength and Rigidity of High Strength Steel
}

\author{
Mitja Schimek ${ }^{1, a}$, Dirk Herzog ${ }^{1, b}$, Dietmar Kracht ${ }^{1, c}$ \\ and Heinz Haferkamp ${ }^{1}$ \\ ${ }^{1}$ Laser Zentrum Hannover e.V. (LZH), Hollerithallee 8, 30419 Hannover, Germany \\ am.schimek@lzh.de, bd.herzog@lzh.de, cd.kracht@Izh.de
}

\section{Keywords: bead-on-plate, overlap welding, laser, rigidity, strength, fatigue}

\begin{abstract}
Nowadays, high requirements are being placed on producing lighter automobiles with a higher strength. To achieve graded strength properties and to improve the rigidity of high strength thin steel sheets, the side effects of laser joining processes can be used. Local physical and geometrical effects which have previously only been observed as side effects can be purposefully used to increase the rigidity and strength of sheet metal structures. By using a focused laser beam with a diameter of several tenths of a millimetre, bead-on-plate and overlap welding seams have been produced. The energy needed to produce this kind of welding seam can be limited to a small area of the workpiece. In comparison to other procedures, the basic material characteristics are retained after welding, the main reason for this being localized heat input. The continual development of laser beam sources to provide higher output powers has extended their spectrum of use in the field of joining technologies. One aim of the research is to produce local physical and geometrical effects with two different laser systems, on the one hand, with an Nd:YAG laser with a maximum output power of $4 \mathrm{~kW}$, and on the other hand with a Yb:YAG laser with an maximum output power of $3 \mathrm{~kW}$. Bead-on-plate and overlap welding seams were produced to demonstrate that rigidity and strength can be increased in metal sheets. The investigations were carried out on two high strength steels H340LA with two different zinc coatings (D and ZE) and TRIP700. The sheets were tested using tensile tests, 3-point bending tests and fatigue strength tests. During the tests, metallographic analyses were carried out. Seven different specimens were investigated, one without bead-on-plate welding seams, and six with different welding geometries, expect the material H340LAZE which was investigated with three various welding geometries. To analyse the complex stress status, investigations of the residual stress and the fracture were done. Calculations of the seam volume were done to be able to calculate the tensile strength for linear bead-on-plate welding seams and the maximum force for bending overlap welding seams. The tensile and bending tests showed that higher forces were needed before failure occurred, e.g. bending the specimens. Furthermore, the investigations showed that the strength of the specimens with welding seams increased, in comparison to the specimens without welding seams. Another result of the experiments is that there is a dependency between the fatigue strength and the position of the seam relative to the direction of the testing force.
\end{abstract}

\section{Introduction}

Advanced joining techniques for high volume automotive productions have been developed to meet increasingly stringent product and production specifications, and because of the increasing diversity of materials in modern vehicles [1]. For example, different grades of high strength steel with reduced sheet thickness, some with different types of surface coating, are used to reduce the weight of a vehicle and to fulfil demands for reduced fuel consumption and emissions. A constant development of industrial production technologies has increasingly leaded to modular construction methods. On the one hand, it is important to reduce the weight, on the other hand to increase the safety of the occupants. One possibility is to strengthen the car body with bead-on-plate welding seams. This aspect is the subject of the research project. In automotive production it is not only necessary to reduce the mass to be moved, but also to increase strength. On the basis of higher 
dynamic and static maximum stress, the focus has recently been placed on increasing machine dynamics by reducing the moved mass. Metallic, high-strength, semi-finished products and construction units are needed if the principal requirements are to be fulfilled $[2,3]$. The continuous development of laser beam sources to provide higher beam output powers and beam quality has extended their spectrum of use in the field of joining technologies. $[4,5]$ With laser beam welding, the high welding speed and low energy input keeps distortion low. On the other hand, rapid cooling of the welding seam results in high hardness, especially with high strength steels [6]. The materials that were tested were within the range of high-strength steels recently developed for the automotive industry [1]. In this research project, especially increasing the strength of high strength steels with bead-on-plate and overlap welding seams was investigated.

\section{Materials}

Experiments began with the micro-alloyed steel H340LAD. This is a hot-galvanized sheet metal with a minimum yield stress of $340 \mathrm{MPa}$. The range for micro-alloyed, fine-grained steels from H260LAD to H420LAD is essentially based on the strength-increasing effect of micro-alloying additions (niobium and/or titanium and carbon). More tests were done with a residual austenite steel TRIP700. This multi-phase steel has a high carbon equivalent, which results in high hardness levels in the fusion zone. Hard phases such as martensite and bainite are placed in a ferritic matrix. Also an additional effect comes into action: The soft austenite transforms into hard martensite when forming at room temperature takes place.

Table 1 shows the chemical composition of H340LAD and TRIP700. The material H340LAZE shows the same mechanical properties as the material H340LAD and was used for the fatigue tests.

Table 1: Chemical composition of H340LAD and TRIP700 [7]

\begin{tabular}{|c|c|c|c|c|c|c|c|c|}
\hline Material & $\begin{array}{l}\mathrm{C} \max . \\
{[\mathrm{wt} \%]}\end{array}$ & $\begin{array}{l}\text { Si max. } \\
{[\mathrm{wt} \%]}\end{array}$ & $\begin{array}{c}\text { Mn max. } \\
{[\text { wt } \%]}\end{array}$ & $\begin{array}{l}\mathrm{P} \max . \\
{[\mathrm{wt} \%]}\end{array}$ & $\begin{array}{l}\mathrm{S} \max . \\
{[\mathrm{wt} \%]}\end{array}$ & $\begin{array}{c}\text { Al max. } \\
{[w t \%]}\end{array}$ & $\begin{array}{l}\text { Ti max. } \\
\text { [wt \%] }\end{array}$ & $\begin{array}{r}\mathrm{Nb} \max . \\
{[\mathrm{wt} \%]}\end{array}$ \\
\hline H340LAD & 0.110 & 0.050 & 1.000 & 0.025 & 0.025 & 0.015 & 0.150 & 0.090 \\
\hline TRIP700 & 0.220 & 1.100 & 2.000 & 0.060 & 0.015 & 1.100 & & \\
\hline
\end{tabular}

In comparison to other steels, these steels show good welding and forming characteristics. The main operational areas for micro-alloyed and residual austenite steels are structural parts for the automobile industry e.g. safety-relevant elements for bumpers. Table 2 shows the mechanical properties of the steels H340LAD and TRIP700.

Table 2: Mechanical properties of H340LAD and TRIP700 [7]

\begin{tabular}{|c|c|c|c|c|}
\hline Steel & $\begin{array}{c}\text { Thickness } \\
\text { s [mm] }\end{array}$ & $\begin{array}{c}0.2 \% \text { Technical } \\
\text { elastic limit } \\
\text { Rp0.2 [MPa] }\end{array}$ & Tensile strength Rm [MPa] & $\begin{array}{c}\text { Elongation at } \\
\text { break } \\
\text { A [\%] }\end{array}$ \\
\hline H340LAD & 1.2 & $340-420$ & $410-510$ & 21 \\
\hline TRIP700 & 1.2 & $410-510$ & $690-790$ & 23 \\
\hline
\end{tabular}




\section{Welding seam geometries}

To achieve varied results, six different weld geometries were produced. One specimen has a single linear welding seam over the complete specimen length $(200 \mathrm{~mm})(\mathrm{A})$. Another specimen has the same seam geometry, but with two parallel welding seams (B). A third sample has three parallel welding seams over the same length $(\mathrm{C})$. Three other non-linear specimens with bead-on-plate welding seams were produced $(\mathrm{D}, \mathrm{E}, \mathrm{F})$. As a reference, a specimen without a welding seam was tested $(\mathrm{G})$. An overview over the bead-on-plate welding seams produced is shown in Fig. 1.

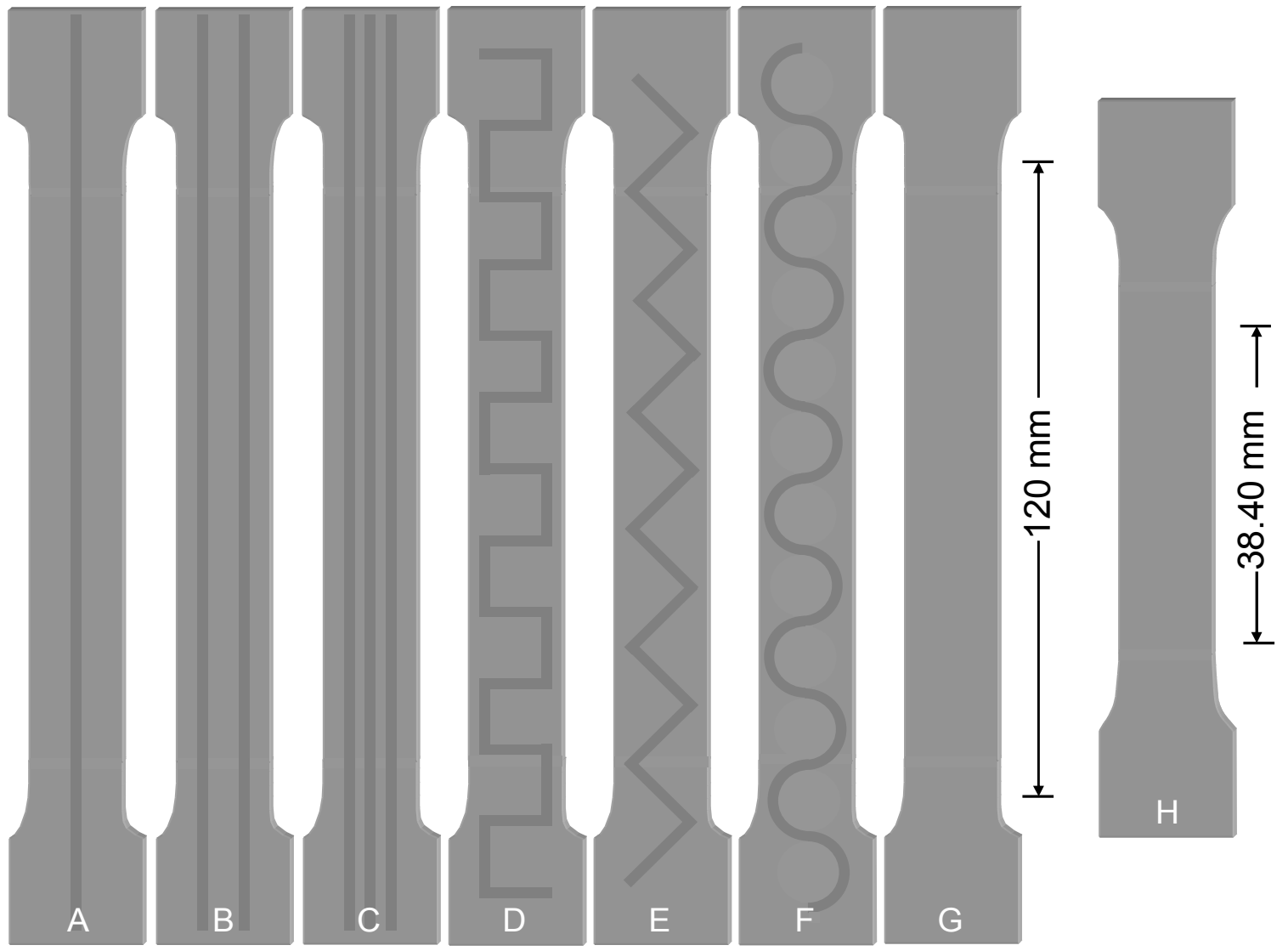

Fig. 1: Specimens with different welding seam geometries for testing

Fatigue strength tests require special specimen geometries as shown in Fig. 1 on the right hand side. Three welding seam geometries A, C and D were tested using this special geometry. The difference between the specimen geometries for static and cyclic tests is that specimen $\mathrm{H}$ has a larger radius in the clamping area than the specimens used for tensile testing. Specimens of the type $\mathrm{H}$ were produced with a larger radius to reduce stress raising notch effects which lead to premature failure in the fixation area. Also, the area of interest on the specimen is much smaller than that of the tensile test specimens.

To achieve the same welding seam quality for all samples, the corners of the specimens D and E have small radii. The welding seam width amounts to $1 \mathrm{~mm}$ on the front face. In the radii, a welding seam width of $2 \mathrm{~mm}$ is measured.

The same welding geometries are used for the overlap welding seams. Because of the zinccoating, a gap of $0.2 \mathrm{~mm}$ between the two sheets is necessary. To obtain comparative results, the specimens with overlap welding seams have the same stress area of $2400 \mathrm{~mm}^{2}$. In Fig. 2, the overlap area with three parallel overlap welding seams is shown. 


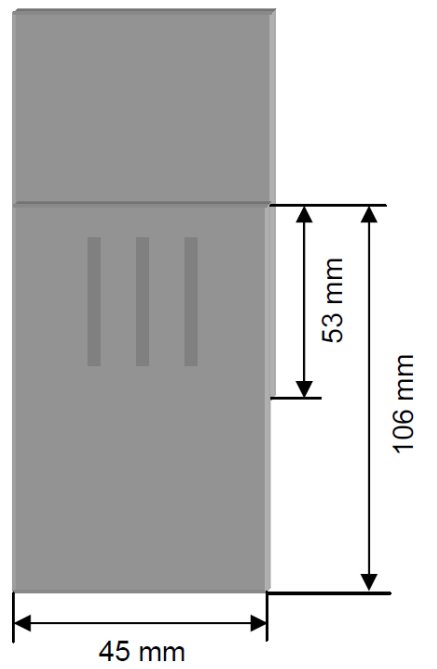

Fig. 2: Specimen geometry for overlap welding seams

The length of the welding seams is about $45 \mathrm{~mm}$. The testing area of the specimens with bead-onplate and overlap welding seams is $53.3 \mathrm{~mm}$. The overlap and the bead-on-plate specimens are labelled the same.

\section{Process}

Welding was carried out using a fibre-coupled Nd:YAG and a Yb:YAG laser. The Nd:YAG laser has a maximum output power of $4 \mathrm{~kW}$ and a fibre diameter of $0.6 \mathrm{~mm}$, while the Yb:YAG laser has a maximum output power of $3 \mathrm{KW}$ and a fibre diameter of $0.15 \mathrm{~mm}$. The focal length of the focusing optics used for welding was $200 \mathrm{~mm}$.

Argon was used as a shielding gas to protect the welding process against environmental influences. This setup allows welding seams to go completely through the specimens, using the deep penetration welding effect. In the starting and final welding phase, power is decreased to avoid welding caldera. For welding bead-on-plate seams with the Nd:YAG laser, the best welding results were achieved using $3.5 \mathrm{~kW}$ laser power and a feed rate of $6.5 \mathrm{~m} / \mathrm{min}$, and for the $\mathrm{Yb}$ :YAG laser, the same feed rate and an output power of $2.8 \mathrm{~kW}$. These parameters were determined in previous tests.

The best parameters for the overlap welding process were found to be: $4 \mathrm{~kW}$ laser power output (Nd:YAG laser) and a feed rate of $4.85 \mathrm{~m} / \mathrm{min}$.

\section{Testing methods}

In order to determine elongation before failure for the selected geometries, comparable tensile tests are carried out. The testing speed for the samples amounts to $10 \mathrm{~mm} / \mathrm{min}$. For each test series with 10 specimens with the same welding geometry, the average is presented. A tensile testing machine is also used for the static tensile and bending tests. The tensile tests were done under elongation control and conform to DIN ISO 10002.

One aim of the bending test is to determine the mechanical rigidity of different structures. The force needed to bend the sheet metals with $10 \mathrm{~mm}$ bead-on-plate and $6.625 \mathrm{~mm}$ overlap welding seams is measured.

To determine the cyclic behaviour of bead-on-plate welded sheets with different weld shapes with the applied force, fatigue tests with geometries $\mathrm{A}, \mathrm{C}$ and $\mathrm{D}$ were undertaken. The fatigue limit is tested with a resonance test machine. In this connection, the stress ratio is held at $\mathrm{R}=0$ with an ultimate numbers of cycles of 5.000.000. All tests are done using the staircase method [8]. An equidistant step of $5 \mathrm{MPa}$ is used. The analysis of the fatigue strength is done with the maximum likelihood method [9]. 
Destructive measurement of residual stress was also performed. During the destructive measurement, such as the borehole method, the flexible spring back is seized and evaluated due to the disturbed equilibrium. With the non-destructive method (e.g. X-ray graphical residual stress measurement) the tension of the metal matrix is determined. This procedure is limited to very near the surface, since steel exhibits the information depth in the range of a few micrometers.

\section{Results}

Metallographic analysis. In order to correlate the mechanical properties with the microstructure of the seam, micrographs were made. Furthermore, hardness tests were done in the base material, the heat affected zone and the fusion zone.

In Fig. 3, a micrograph of a sheet metal H340LAD is shown. Number one marks the base material, number two the heat affected zone and number three the fusion zone.

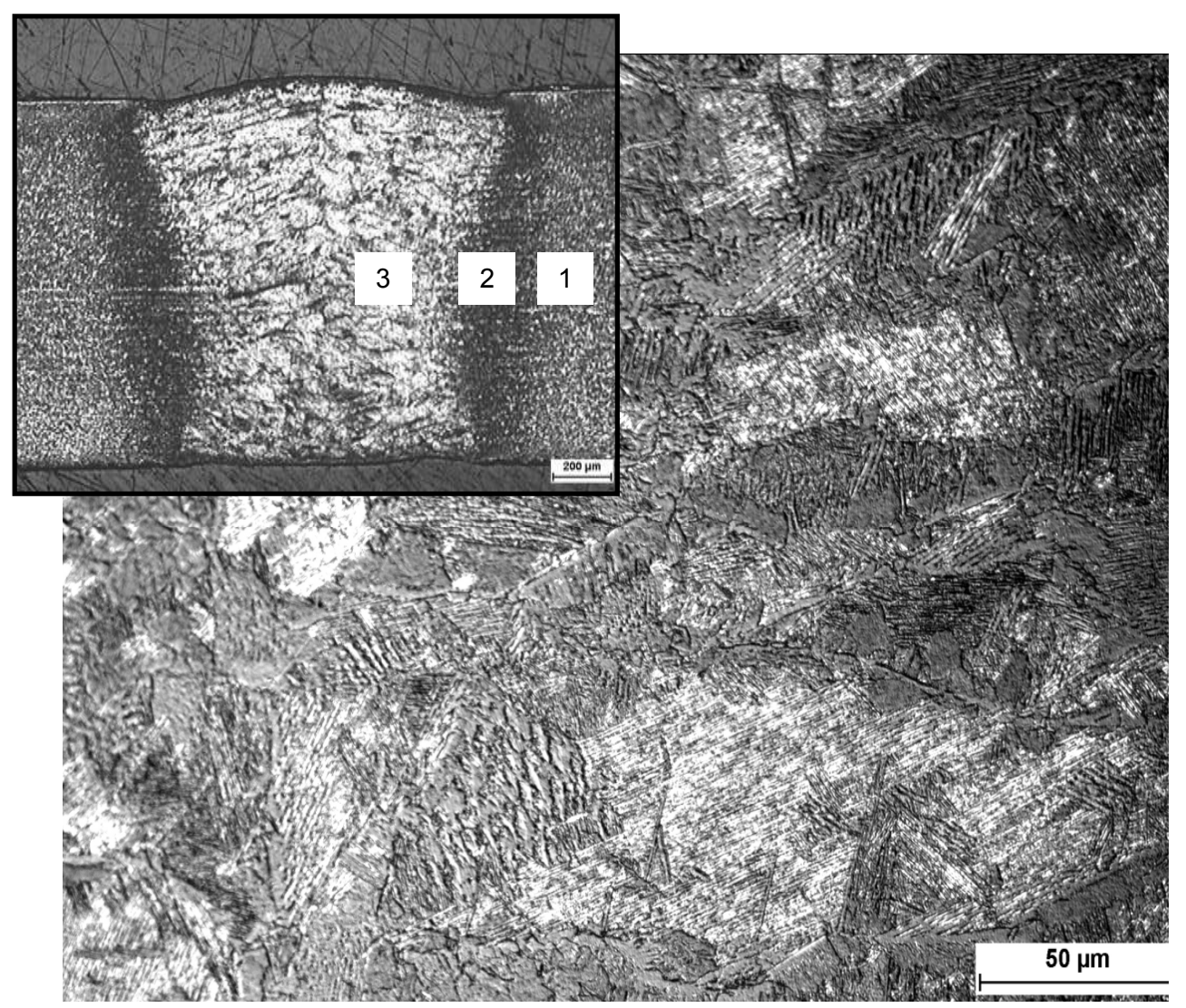

Fig. 3: Micrograph of an H340LAD welding seam (Nd:YAG)

The base material of H340LAD is fine grained ferrite-perlitic. After the heat influence of the laser beam, the structure is coarse-grained with martensitic areas.

Following each point, 5 hardness measurements were taken in all structure zones.

Hardness when using a Nd:YAG laser was found to be $180 \mathrm{HV} 0.2$ for the base material (1), $230 \mathrm{HV} 0.2$ for the heat affected zone (2) and $350 \mathrm{HV} 0.2$ for the fusion zone (3). One result is that the hardness increases with a maximum in the fusion zone. The hardness increases by 135 HV0.2, and is mainly responsible for the strengthening effects observed. The results of the hardness tests are shown in Fig. 4. 


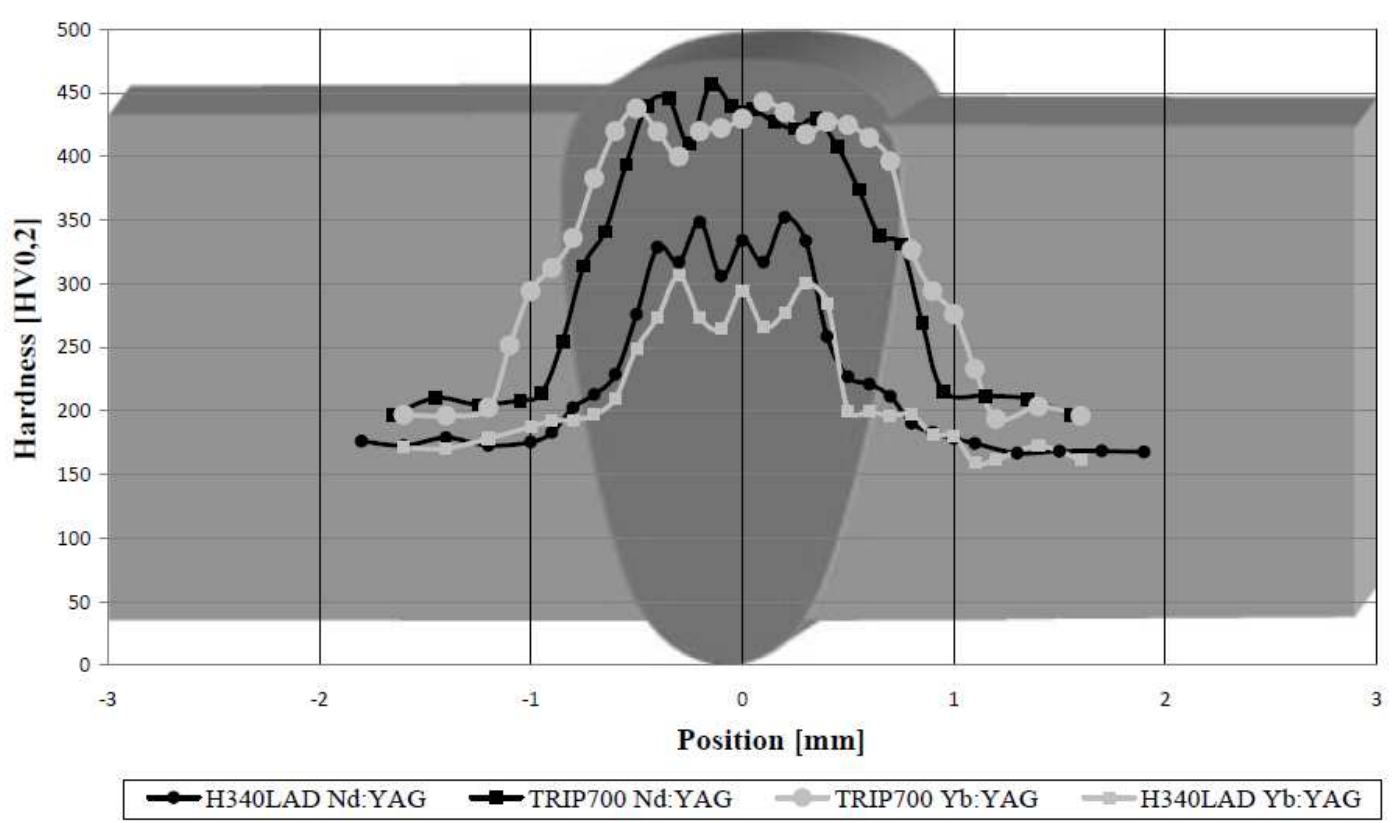

Fig. 4: Increasing of hardness after the welding process

Identical hardness for the base material and the heat affected zone were found after using a $\mathrm{Yb}$ :YAG laser. In the fusion zone the hardness was measured at $280 \mathrm{HV} 0.2$. The hardness increases by $80 \mathrm{HV} 0.2$. In comparison to the hardness of the fusion zone that was produced using an Nd:YAG laser, hardness decreased by 55 HV0.2.

In Fig. 5, the micrograph of a TRIP700 overlap welding seam is shown. The numerical identification is the same as in Fig. 3. Number one shows the base material, number two the heat affected zone, number three the fusion zone and additionally number four the $0.2 \mathrm{~mm}$ gap. The fusion zone consists of lanceted martensite after tempering with rounded needles. The bright textures show the intemperate martensite. After the heat input, low fractions of residual austenite exist. The hardness of the structure zone was found to be $210 \mathrm{HV} 0.2$ for the base material (1), $360 \mathrm{HV} 0.2$ for the heat affected zone (2) and $450 \mathrm{HV} 0.2$ for the fusion zone (3). 


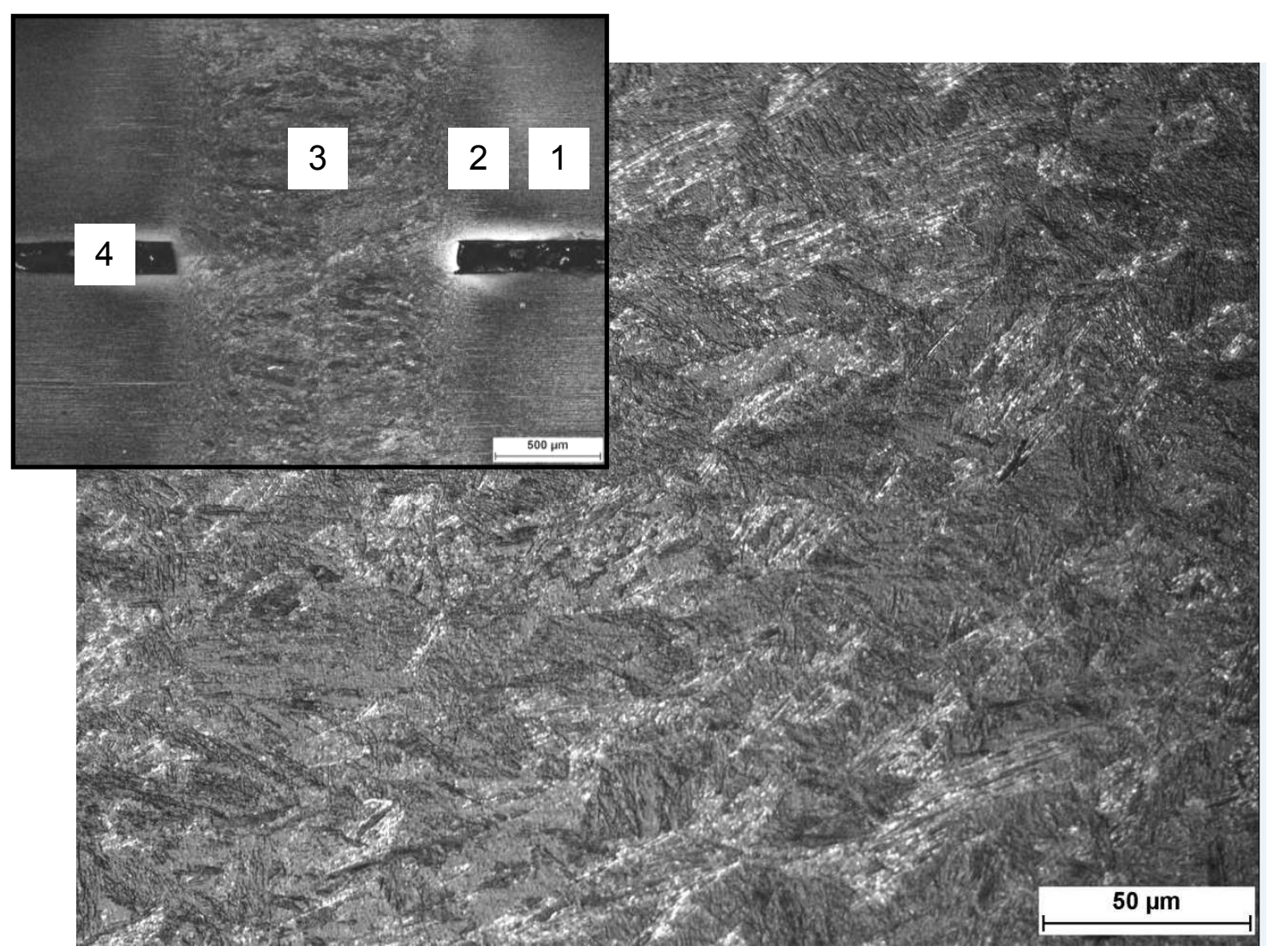

Fig. 5: Micrograph of a TRIP700 overlap welding seam (Nd:YAG)

The hardness that was increased by using a Yb:YAG laser was nearly the same for all measured values.

Tensile Tests of bead-on-plate welding seams. The tensile tests are carried out to determine the difference between the stress and the extensions of all bead-on-plate and overlap welding seams. In Fig. 6, a tensile test after the breakage of a rectangle zigzag welding seam specimen is shown.

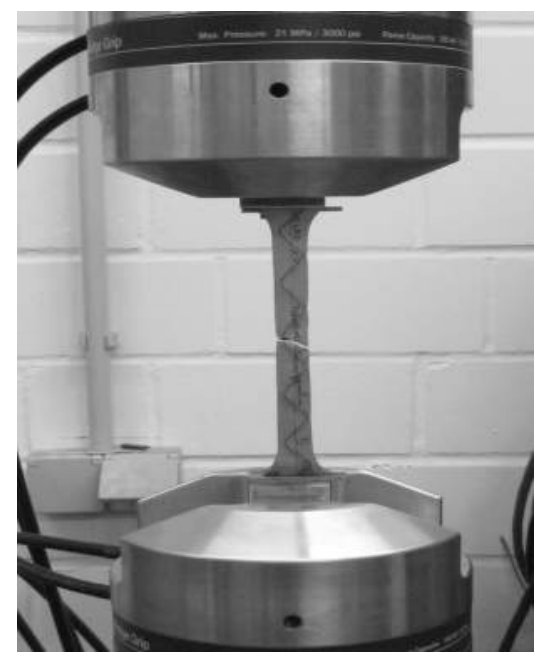

Fig. 6: Tensile test with a rectangle zigzag welding seam specimen

In Fig. 7, the results of the measured stress-strain characteristics of the material H340LAD with bead-on-plate welding seams produced with the Nd:YAG laser are shown. 


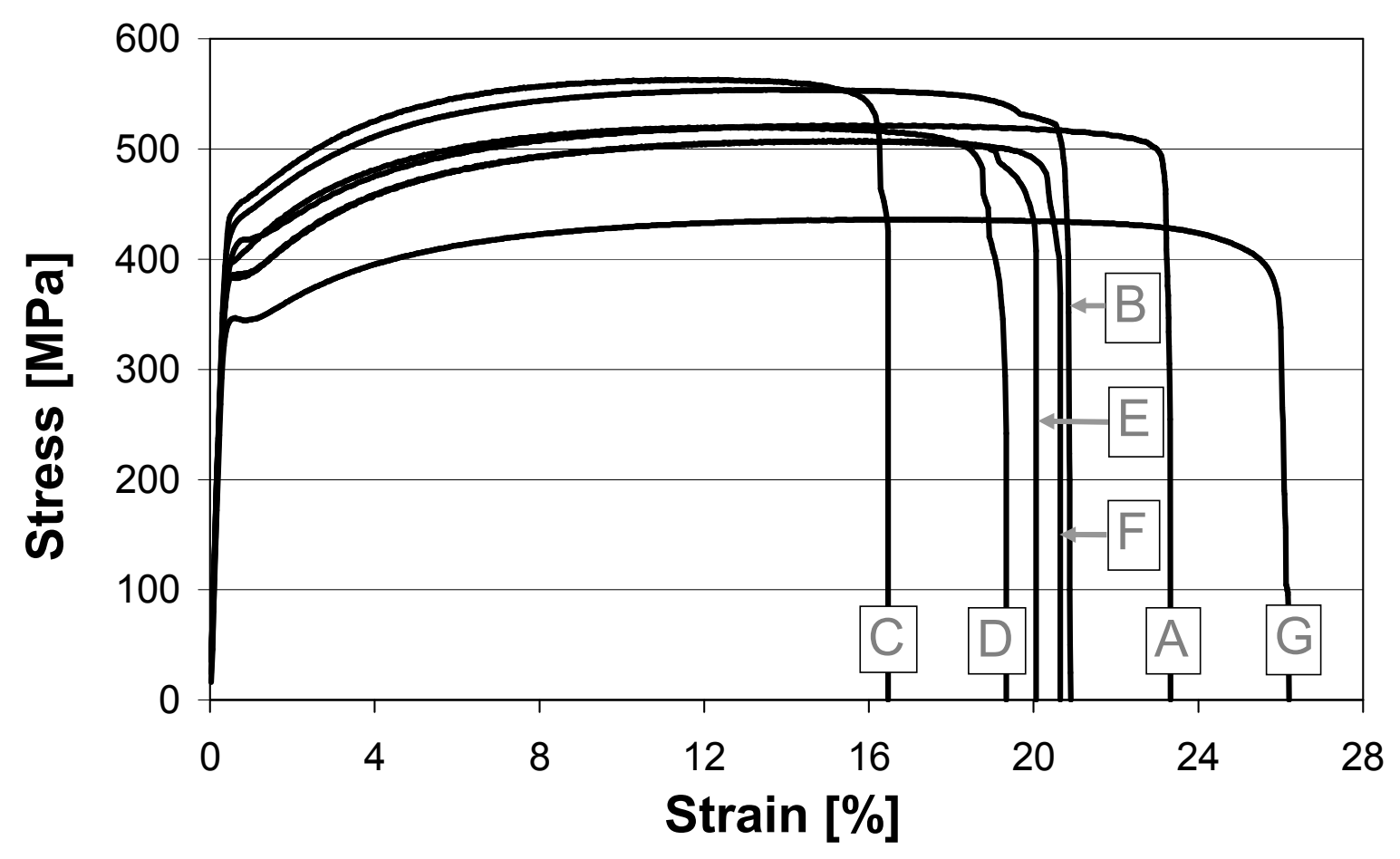

Fig. 7: Stress-Strain-Curves of H340LAD bead-on-plate specimens (Nd:YAG)

Specimen C, with three parallel bead-on-plate welding seams, exhibits the highest tensile strength of $564 \mathrm{MPa}$. Because of the high tensile strength, the specimen has a strain value of $16.5 \%$. In contrast to the base material (specimen $\mathrm{G}$ ), there is a strain reduction of at least 10 percentage points. However, the tensile strength increases by $127 \mathrm{MPa}$, due to the local bead-on-plate seams.

Similar tensile and elongation to failure values resulted from the measurements of the specimens $\mathrm{B}, \mathrm{D}, \mathrm{E}$ and F. These specimens show a tensile strength between 508 and $520 \mathrm{MPa}$, with an elongation of 19 to $21.5 \%$. The base material examined in this testing period has an elongation at rupture of $26 \%$. An interesting point to focus on is the comparison between the specimens A, B and C. Specimen A, with one linear bead-on-plate welding seam, exhibits tensile strengths of $543 \mathrm{MPa}$. Between specimen $\mathrm{A}$ and specimen $\mathrm{B}$, and correspondingly between $\mathrm{B}$ and $\mathrm{C}$, there is a difference of $10 \mathrm{MPa}$. A strength increase can be obtained by applying bead-on-plate welding seams.

One important result is the comparison between the specimen $\mathrm{C}$ and the base material. The kind of welding seams on specimen $\mathrm{C}$ increase the strength by $40 \%$ with only a slight reduction in maximum elongation.

To investigate the failure behaviour of specimens with bead-on-plate welding seams, the first tensile specimens were not welded over the complete length. Fig. 8 schematically shows an example of a tensile specimen with three linear bead-on-plate welding seams. The specimen is divided into 3 parts: The first area (I), which present the specimen cross-section of the unaffected base material and a second area (II), with bead-on-plate welding seams, and thus in some areas a change in the microstructure induced (transition zone), and a third area (III), which is fully equipped with bead-on-plate welding seams. As expected, at first a failure starts at the transition zone (area II), because the discontinuous transition effect in the material properties at the beginning of bead-on-plate welding seams functioned as a metallurgical notch [10]. By optimizing the welding start-or-end parameters, a continuous, steady transition of the mechanical properties could be achieved, that occurred failures in the first field. Accordingly, there is a crack failure in the base material. 


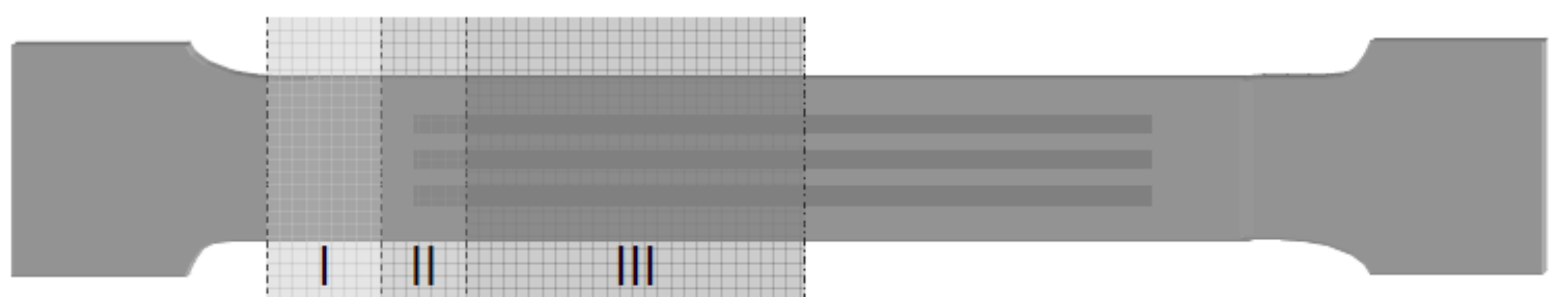

Fig. 8: Stress-Strain-Curves of H340LAD bead-on-plate specimens (Nd:YAG)

In contrast to previous work, in these investigations, the rupture starts in the middle of all specimens and spreads in both directions. Following this, tensile tests were made with residual austenite steel TRIP700 produced by the same laser. The results for this material are shown in Fig. 9.

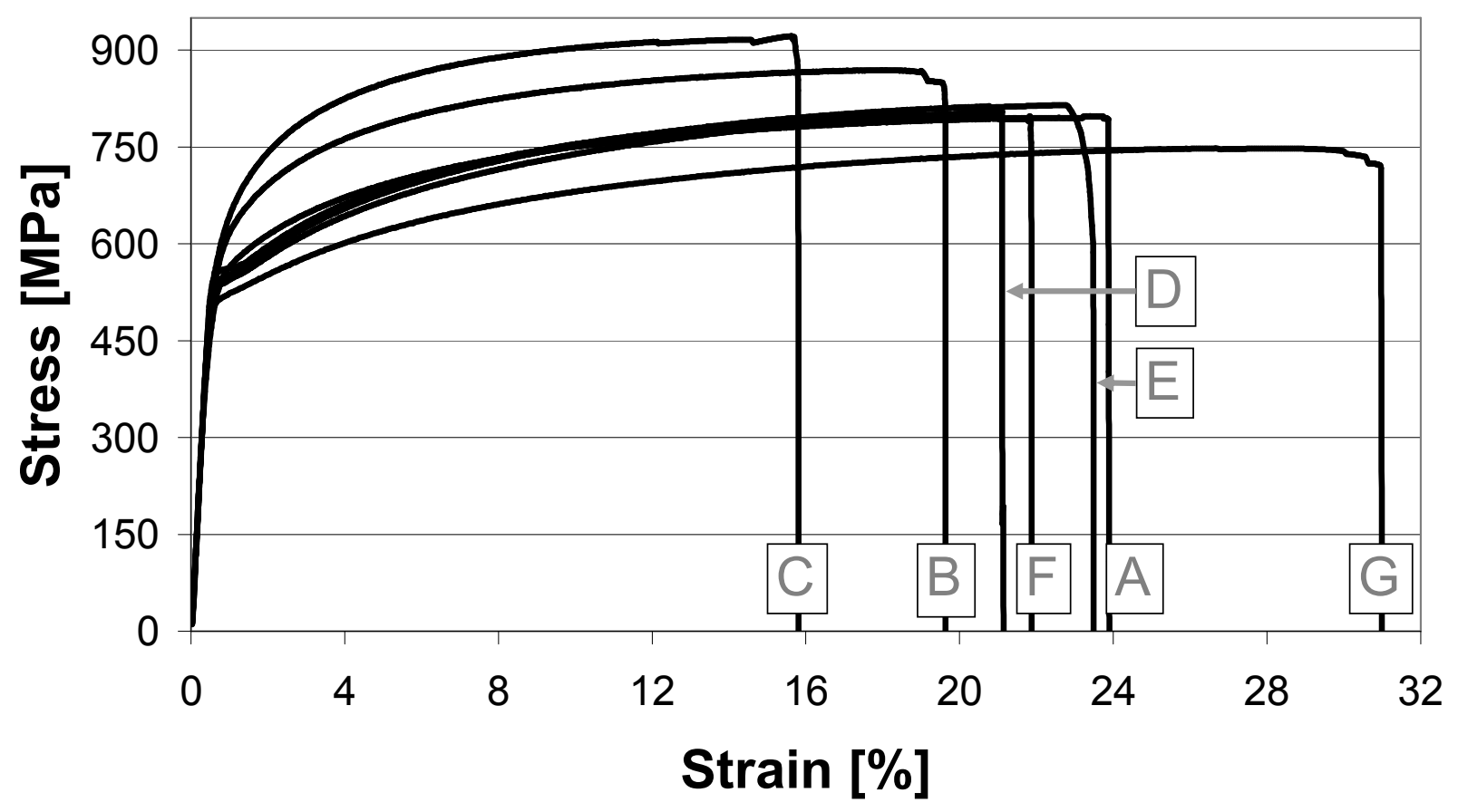

Fig. 9: Stress-Strain-Curves of TRIP700 bead-on-plate specimens (Nd:YAG)

The base material exhibits tensile strengths of $748 \mathrm{MPa}$ with a maximum strain of $31 \%$. This is in the range of the typical mechanical properties. Specimen $\mathrm{C}$ exhibits the highest tensile strength of $922 \mathrm{MPa}$. After the base material, the next highest tensile strength is shown for specimen A, with one linear bead-on-plate welding seam. The tensile strength increases by $50 \mathrm{MPa}$.

Fig. 10 shows the results of the measured stress-strain characteristics of the material H340LAD with bead-on-plate welding seams produced with a Yb:YAG laser. 


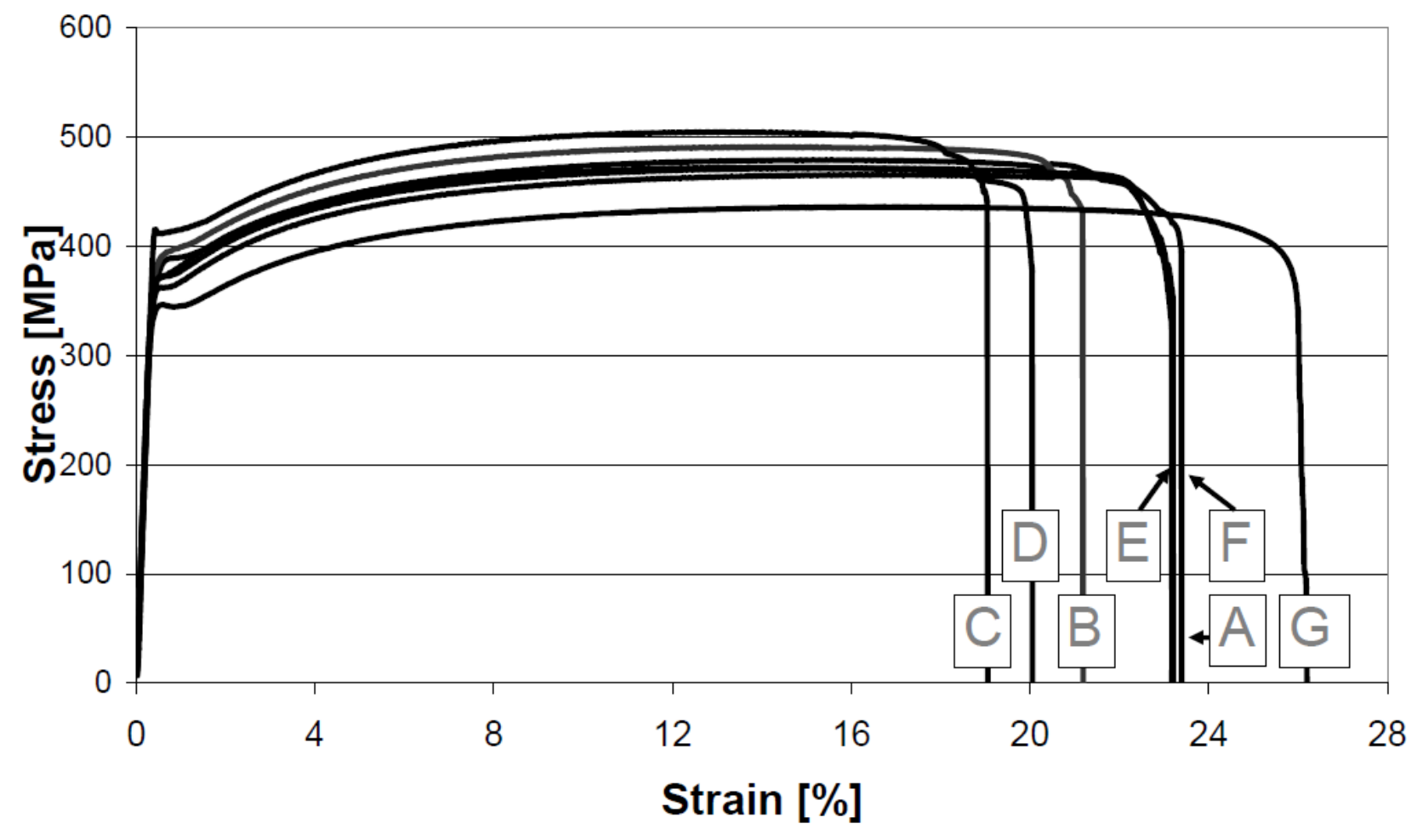

Fig. 10: Stress-Strain-Curves of H340LAD bead-on-plate specimens (Yb:YAG)

As the results before (Fig. 7), the specimen $\mathrm{C}$ with three parallel bead-on-plate welding seams exhibits the highest tensile strength of $513 \mathrm{MPa}$. Because of the high tensile strength, the specimen has a strain value of $19 \%$. In contrast to the specimen $\mathrm{G}$, there is a strain reduction of at least 27 percentage points. However, the tensile strength increases by $76 \mathrm{MPa}$, due to the local bead-onplate seams.

A lower strength increase resulted from the measurements of the specimens B, D, E and F.

These specimens show a tensile strength between 453 and $480 \mathrm{MPa}$, with an elongation of 20 to $23.6 \%$. Specimen A, with one linear bead-on-plate welding seam, exhibits tensile strengths of $458 \mathrm{MPa}$. The kind of welding seams on specimen $\mathrm{C}$ increase the strength by $18 \%$ with a slight reduction in maximum elongation.

Following, the results of the tensile test produced by using the $\mathrm{Yb}$ :YAG laser of the residual austenite steel TRIP700 are shown in Fig. 11.

As before, the base material exhibits tensile strengths of $748 \mathrm{MPa}$ with a maximum strain of $31 \%$. Specimen $\mathrm{C}$ exhibits the highest tensile strength of $882 \mathrm{MPa}$. In comparison to the specimens produced using an Nd:YAG laser, the strength increase is $20 \%$ lower.

Specimen A exhibited a tensile strength of $798 \mathrm{MPa}$. The tensile strength increases by $50 \mathrm{MPa}$. The other bead-on-plate welding seam geometries exhibited similar tensile and elongation values between the specimen $\mathrm{G}$ and specimen $\mathrm{C}$. 


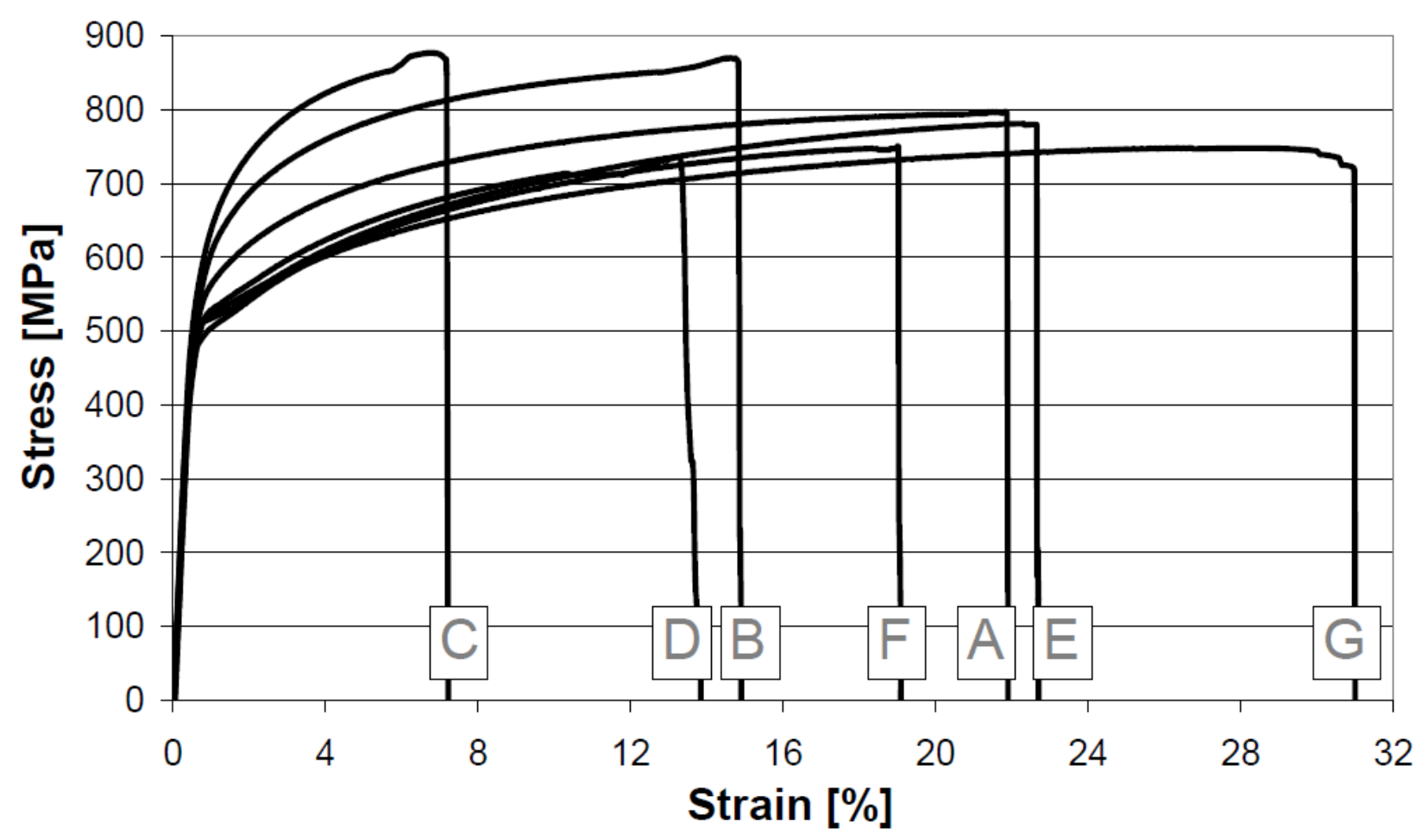

Fig. 11: Stress-Strain-Curves of TRIP700 bead-on-plate specimens (Yb:YAG)

One result is that the strength increase is reduced if an Yb:YAG laser was used. The results showed a high increasing of strength using an Nd:YAG laser. One reason for the effect of different increases between the $\mathrm{Nd}: \mathrm{YAG}$ and $\mathrm{Yb}: \mathrm{YAG}$ laser is the smaller weld pool during the welding process when using the $\mathrm{Yb}: \mathrm{YAG}$ laser.

Fatigue strength tests. The first fatigue strength tests were done on specimens A, C, D and the base material G of H340LAZE. The results of the fatigue strength tests are depicted in Fig. 12.

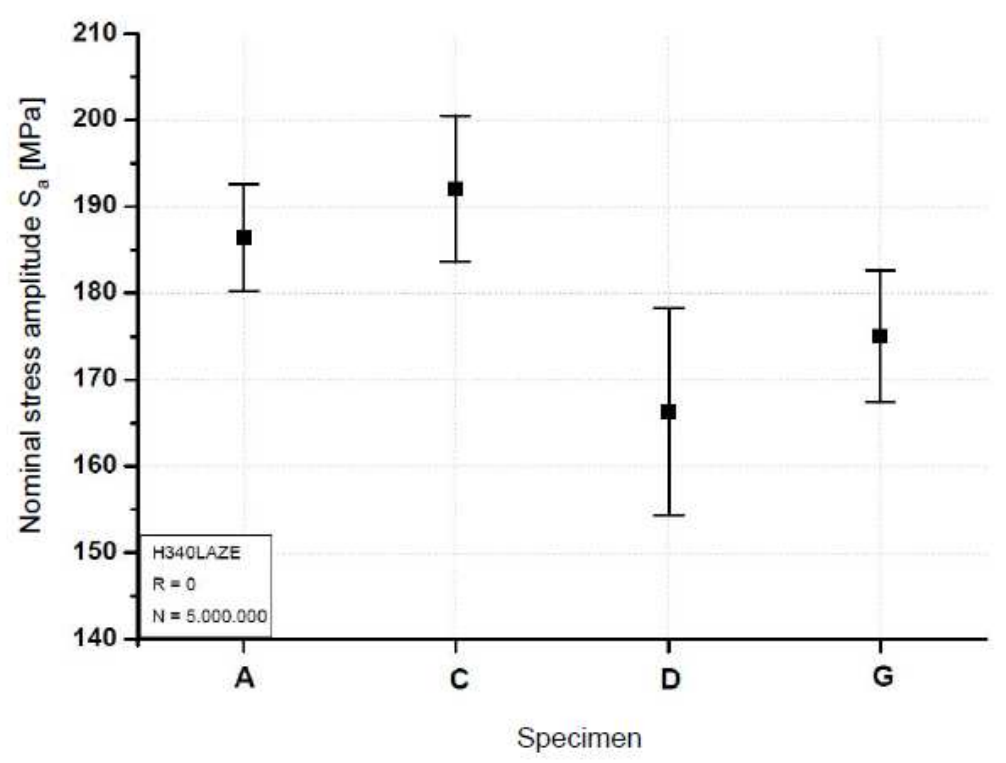

Fig. 12: Fatigue strength test results of H340LAZE bead-on-plate specimens, $N=5.000 .000$

The length of the lines shows each specimen's scatter range during the fatigue tests. The point displays the average nominal stress amplitude. Specimen $\mathrm{D}$ exhibits the lowest average fatigue strength, amounting to $166 \mathrm{MPa}$ and a scatter range of $24 \mathrm{MPa}$. At $186 \mathrm{MPa}$, specimen A has a higher average nominal stress amplitude. It has the smallest scatter range at $12 \mathrm{MPa}$ compared to $\mathrm{D}$ 
and C. The highest average nominal stress amplitude is shown for specimen $\mathrm{C}$ at around $192 \mathrm{MPa}$. Furthermore, this type of specimen exhibits a smaller scatter range, at $17 \mathrm{MPa}$, than specimen D. In comparison to the all tested specimen is specimen G. This specimen is the base material and exhibits fatigue strength of $175 \mathrm{MPa}$ with a scatter range at $15 \mathrm{MPa}$.

The most common point of failure for the welding seam is shown in Fig. 13, which is exemplary of the other welding seams tested.
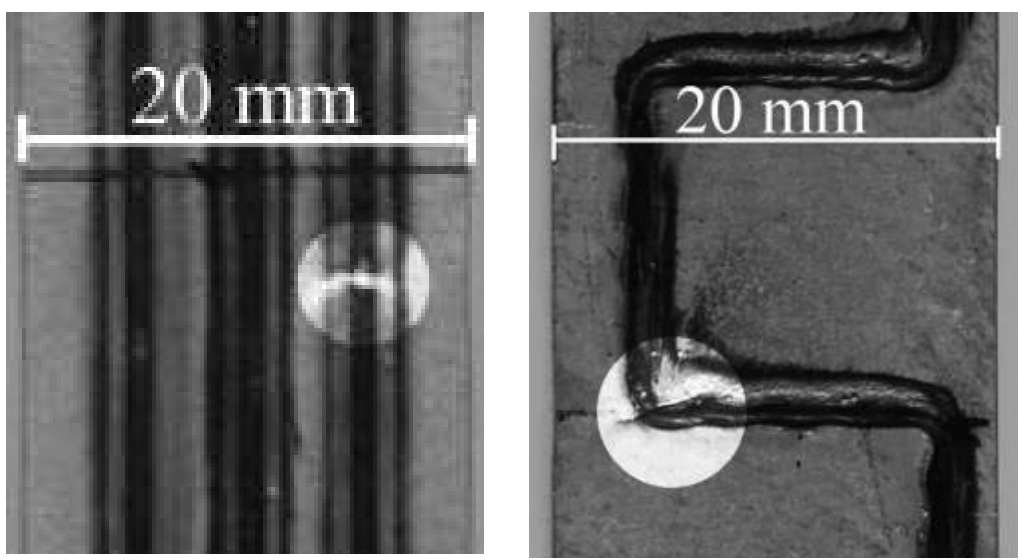

Fig. 13: Point of failure in fatigue test, specimen C and D

The point of failure of every rectangular welded specimen is on an edge of the seam. Fig. 14 shows a schematic stress-strain-curve as result of strain controlled tests.

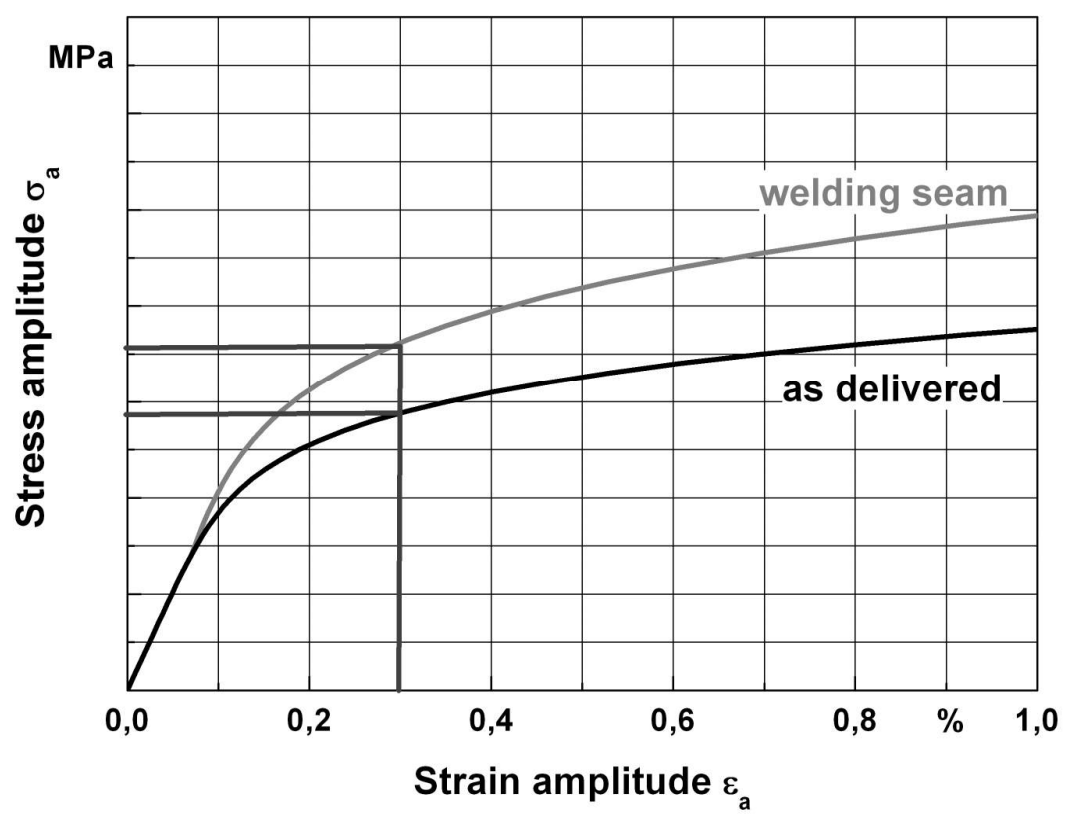

Fig. 14: Schematic stress-strain-curve of strain controlled tests

The bold-line curve is the material as delivered, and the curve above represents the welding seam specimen.

The welding seam is subjected to identical strain in the direction of stress as the material as delivered. But in this case, the stress amplitude for the welding seam is higher than in the material as delivered. This is one reason for the failure of the welding seam.

Residual stress analysis. To obtain statements about the residual stress investigations with specimens before and after, the fatigue strength tests were carried out. First, one specimen without bead-on-plate welding seams was investigated. The results are shown in Fig. 15. 


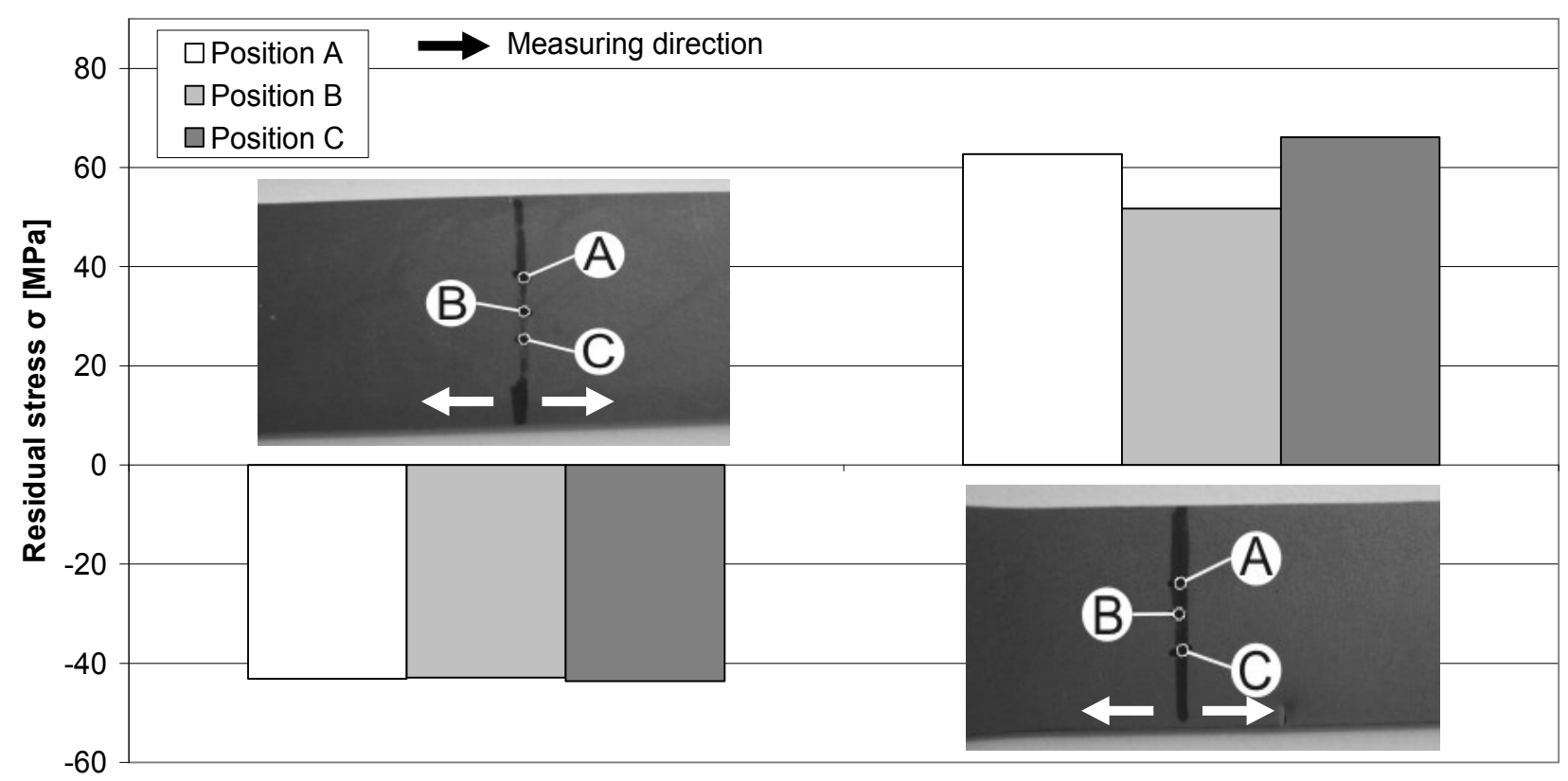

Fig. 15: Residual stress of specimen $\mathrm{G}$ before and after the fatigue strength test

On the left side of the graph, the untested fatigue strength specimen is shown. The results of the residual stress test show that at all measuring points the same negative values (compressive stress) were measured. The tested point A exhibits a residual stress of $-43 \mathrm{MPa}$. On the right side of the graph, the residual stress of specimen $G$ after the fatigue strength test is shown. In comparison to the left specimen, the measuring points all show a positive stress (tensile stress). The middle position $\mathrm{B}$ of the right specimen shows less stress (52 MPa) than position A (62 MPa) and $\mathrm{C}(69 \mathrm{MPa})$. This effect results from the constriction near the specimen border.

A crack at the border of Specimen B that was developed during the fatigue strength test is shown in Fig. 16.

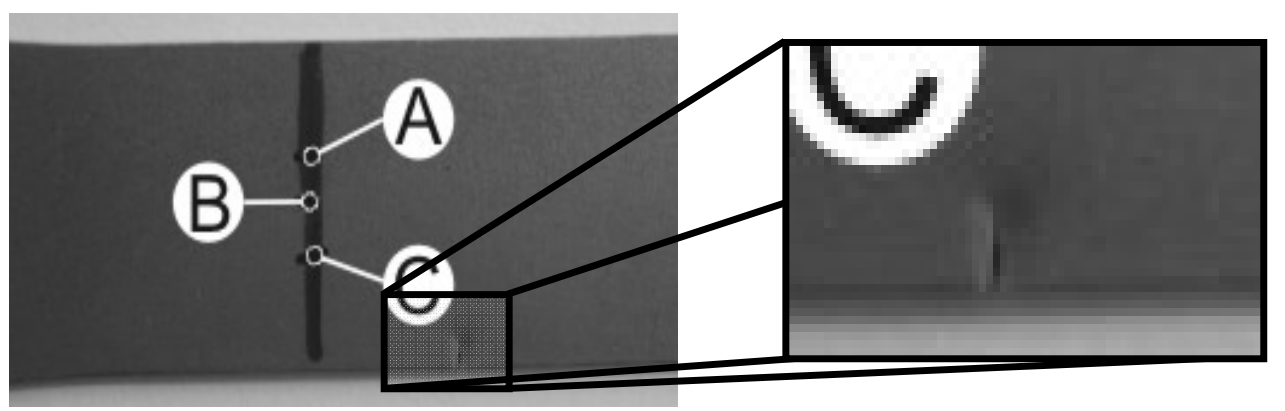

Fig. 16: Specimen G without bead-on-plate welding seams after the fatigue stress test, and a crack at the border of the specimen 
More investigations were done with the specimen with one linear bead-on-plate welding seam (specimen A). The results of the residual stress before and after the fatigue stress are shown in Fig. 17.

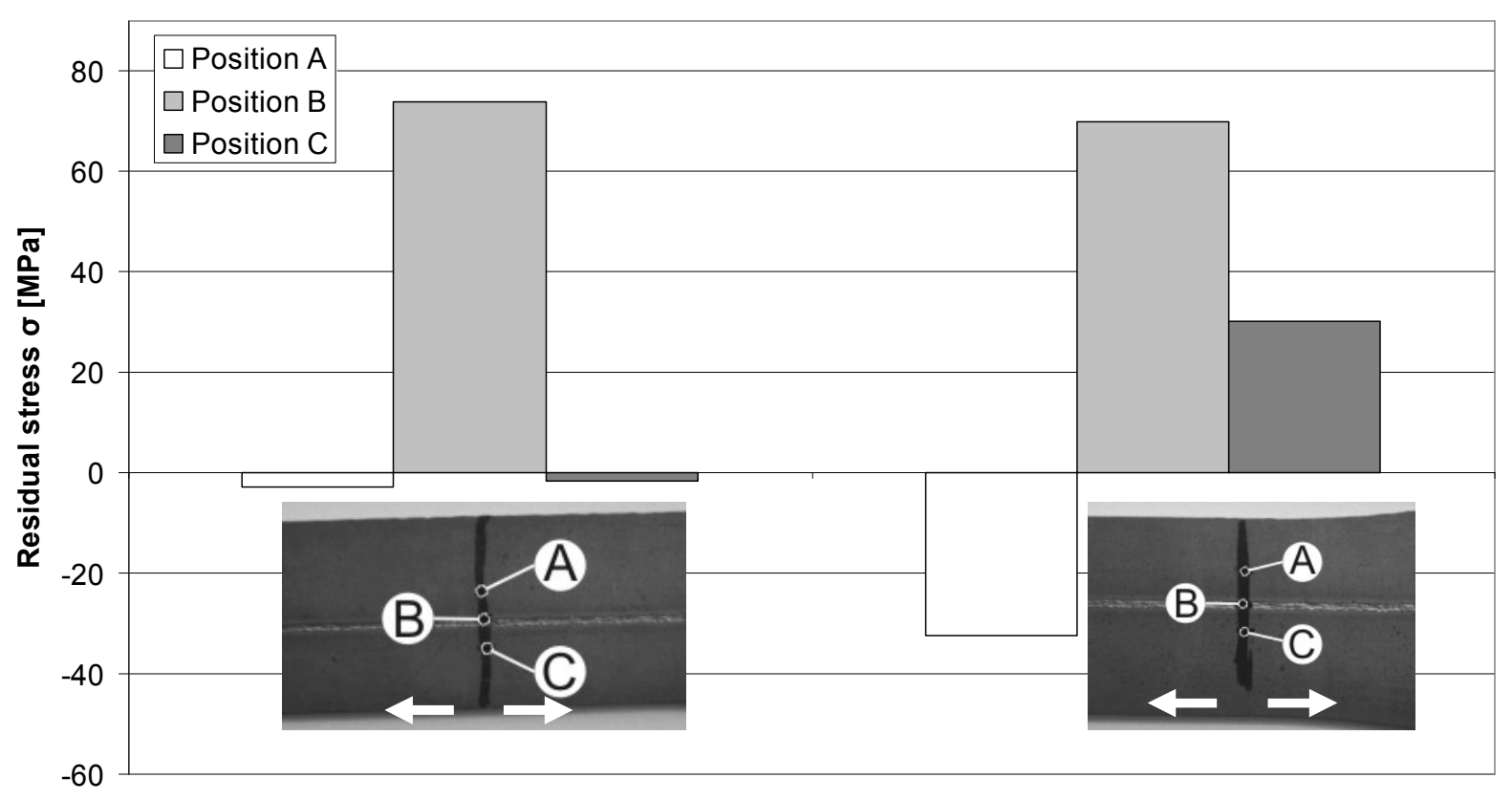

Fig. 17: Residual stress of specimen with one bead-on-plate welding seam before (left) and after the fatigue strength test (right)

The graph on the left side shows the results of the specimen before the fatigue strength test was done. In comparison to the left Specimen in Fig. 17, the bead-on-plate welding seam (position B) effects a stress direction change from $-43 \mathrm{MPa}$ (compressive stress) up to $74 \mathrm{MPa}$ (tensile stress). At positions $\mathrm{A}$ and $\mathrm{C}$, a residual stress of $-2 \mathrm{MPa}$ was measured. Due to the one linear bead-on-plate welding seam in the middle of the Specimen $\mathrm{C}$ tensile stress with $73 \mathrm{MPa}$ exhibited. After the fatigue stress test, the compressive stress at Position $\mathrm{C}$ changed in tensile stress (31 MPa). Only point A exhibited a higher compressive stress of $33 \mathrm{MPa}$.

Deformation measurement. In order to show the strain distribution on the different specimens, the samples were investigated using ESPI (electronic speckle pattern interferometer). ESPI uses the coherence of the laser light to measure the deformation of an object. The area that should be measured will be illuminated with two laser sources of the same wavelength. For the analyses of the deformation, specimens have been manually elongated up to the position that was needed. The tensile test was stopped, to obtain a start picture. For the final picture, the elongation of the specimen was increased by about $5 \mu \mathrm{m}$. The ESPI measure head and one specimen during the tensile test are shown in Fig. 18. 


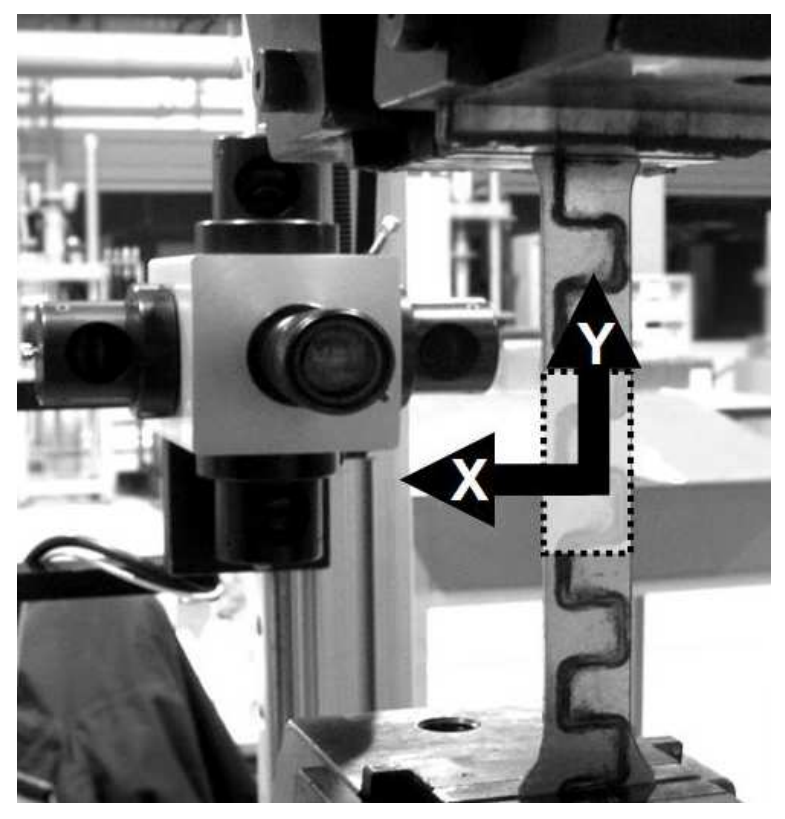

Fig. 18: ESPI equipment and one specimen during the tensile test for the deformation measurement

Furthermore, the measurement directions are marked for the deformation test on the specimen.

The functionality of the measurement method is demonstrated in Fig. 19.

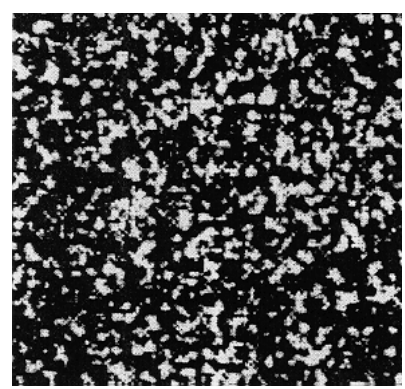

Reference status

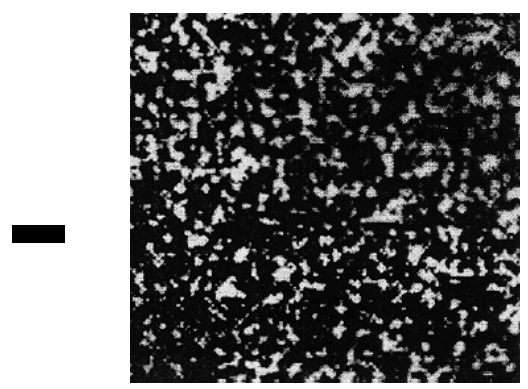

Deformed object

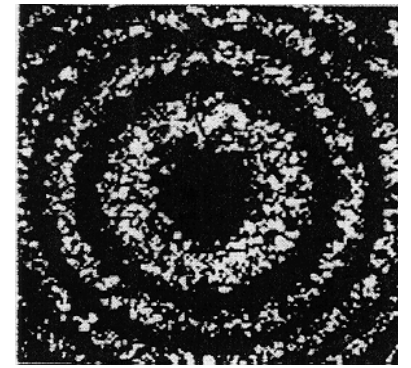

Intensity sample

Fig. 19: Functionality of the deformation measurement

At the beginning of the investigations, a reference picture is made of the area to be measured. The figure of the reference status is considered as the starting specimen. Afterwards, the force of the tensile test is increased, and the specimen is deformed over an elongation of $2 \mu \mathrm{m}$. Following this, another picture of the deformed specimen is made. To obtain the picture of displacement, both pictures are to be subtracting (Fig. 19). The result is a figure of the intensity sample. The generated markings conform to the points of the same displacement.

In Fig. 20, one specimen with three parallel welding seams is shown during ESPI analysis. The picture on the left shows deformation for the X-direction, and the picture on the right the Y-direction. 


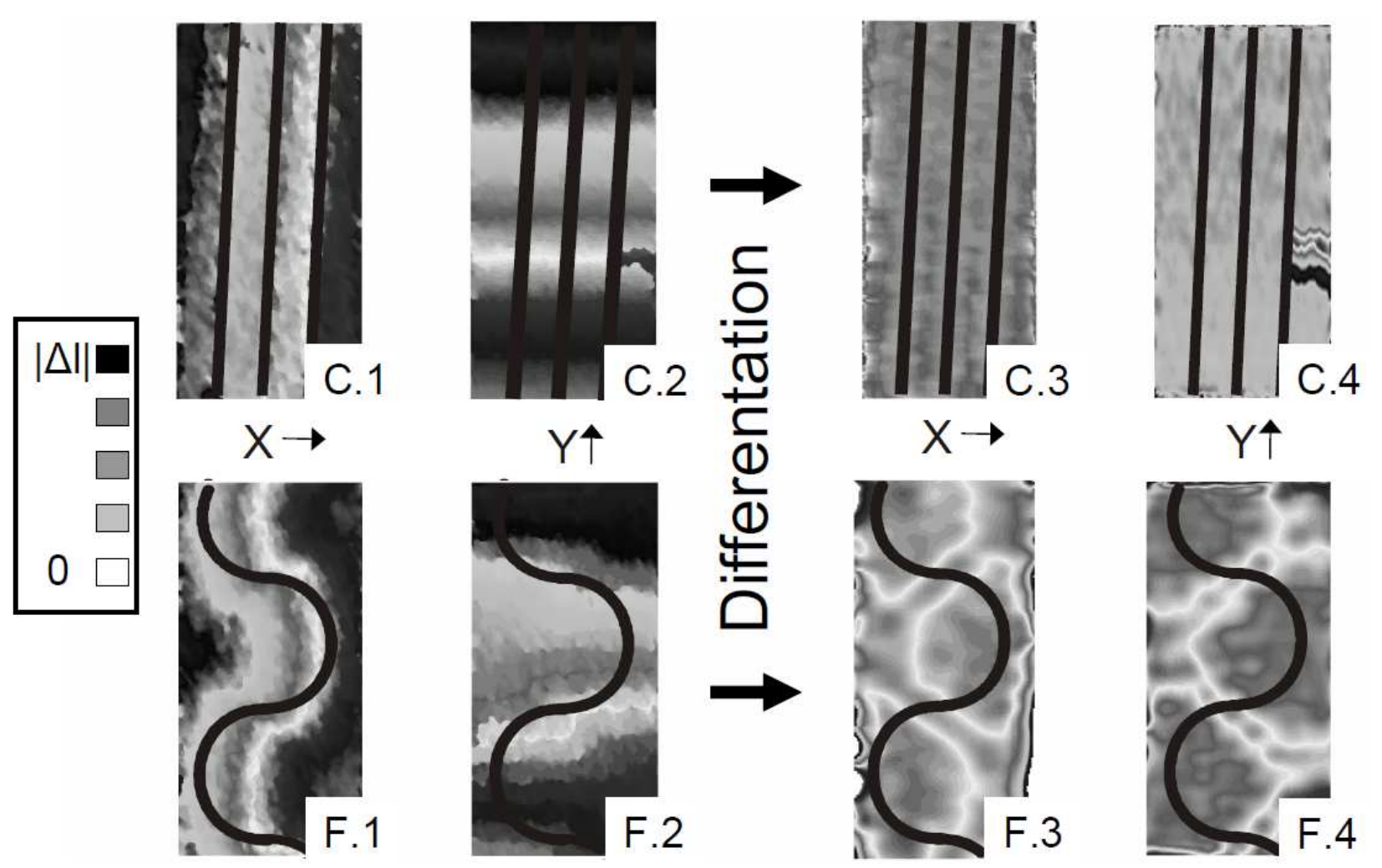

Fig. 20: ESPI analysis of the specimens $\mathrm{C}$ and $\mathrm{F}$

Before the test starts, it is necessary to define the surface zero at the middle of the specimen. The light area in the middle of the picture of the specimen with three parallel welding seams (pictures C.1 and C.2) shows minimum deformation during the tensile test. The darker the colours, the higher the deformation measured. In the $\mathrm{X}$ direction, the highest deformations for these kinds of structures are at the borders of specimen $\mathrm{C}$. The same effect took place in the Y direction, but there as strain. The differentiated figures of specimen C (C.3 and C.4) show that uniform strains over the total area took place. This homogeneous effect was observed on all specimens with linear welding seams. In contrast to the linear welding seams, the ESPI analyses are not homogeneous in the testing crosssection (pictures F.1 and F.2). The influence of the wave seam geometry becomes apparent. In both pictures, the dark grey colours represent the highest deformation of the specimen. The different welding seams have a decisive influence on the deformation of the specimen F.3 and F.4. 
Seam volume. The seam volume is necessary for calculating the tensile strength for linear bead-onplate welding seams. In conjunction with a metallographic specimen, the cross-section polish appears.

In Fig. 21, the cross-section polish of H340LAD with the lengths of different areas is shown.

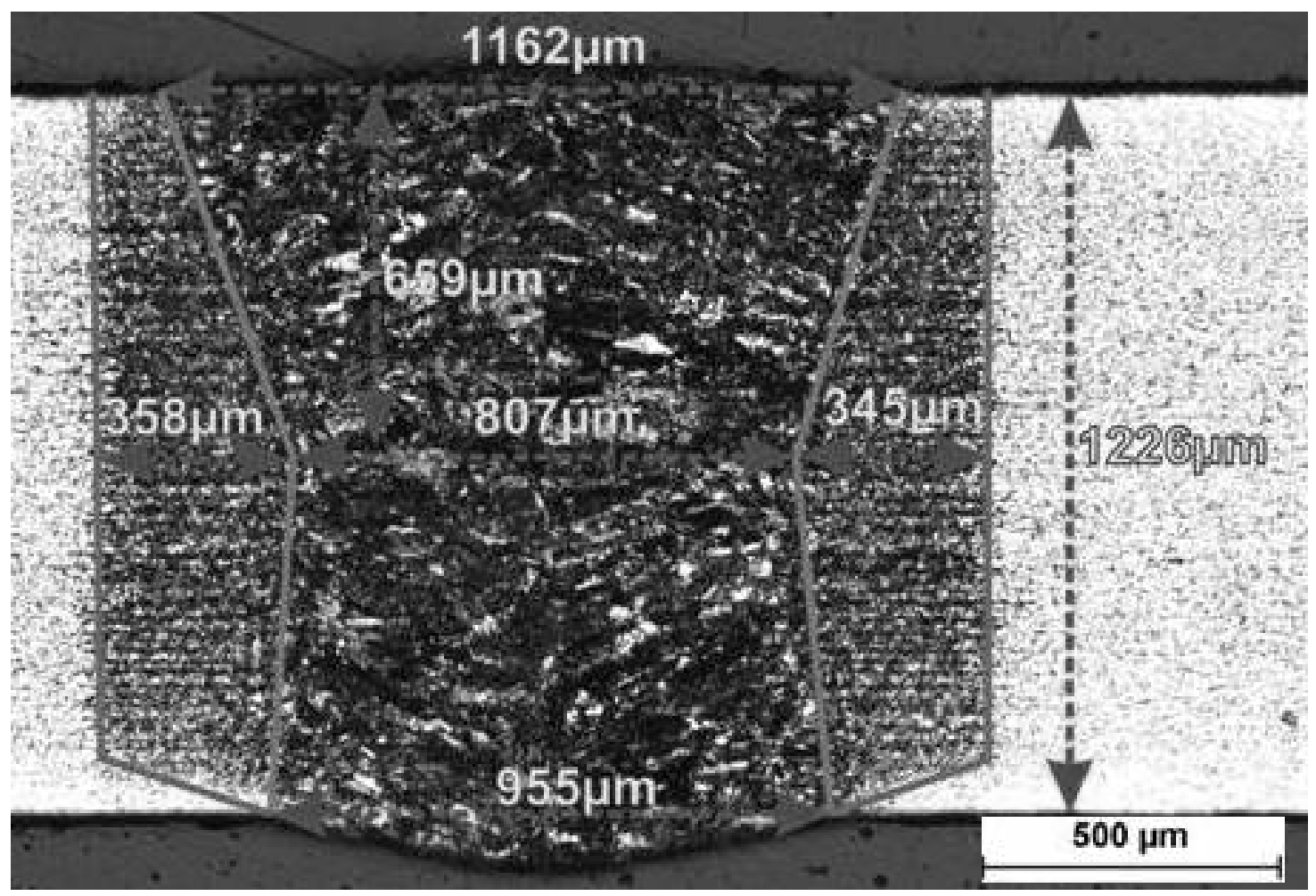

Fig. 21: Cross-section polish of H340LAD with the lengths of different areas

The sheet thickness was measured to be $1.23 \mathrm{~mm}$. For this sheet metal, the heat affected zone exhibits a maximum width of $0.36 \mathrm{~mm}$. The welding seam surface has a width of $1.16 \mathrm{~mm}$, the middle of the welding seam a width of $0.8 \mathrm{~mm}$ and the welding seam bottom surface width is $0.9 \mathrm{~mm}$. Following, the results of the seam volumes measurement were calculated. The results of the calculation are presented in Table 3.

Table 3: Seam volumes of the material H340LAD and TRIP700 after the welding process

\begin{tabular}{|c|c|c|c|c|}
\hline Material & Laser system & $\begin{array}{c}\text { Welding seam } \\
{\left[\mathrm{mm}^{2}\right]}\end{array}$ & $\begin{array}{c}\text { Heat } \\
\text { affected zone } \\
{\left[\mathrm{mm}^{2}\right]}\end{array}$ & $\begin{array}{c}\text { Total } \\
{\left[\mathrm{mm}^{2}\right]}\end{array}$ \\
\hline H340LAD & Nd:YAG & 1.148 & 0.703 & 1.851 \\
\hline TRIP700 & Nd:YAG & 1.152 & 0.446 & 1.598 \\
\hline H340LAD & Yb:YAG & 1.080 & 0.843 & 1.923 \\
\hline TRIP700 & Yb:YAG & 0.962 & 0.759 & 1.721 \\
\hline
\end{tabular}

The total surface area of the welding seams that were produced using an Nd:YAG laser was calculated to be $1.85 \mathrm{~mm}^{2}$ for the material H340LAD and $1.6 \mathrm{~mm}^{2}$ for TRIP700. These values are the results of the addition of the welding seam surface and the heat affected zone. Minimal variations of the total welding seam volumes between the two materials exhibited of the different material- properties and alloying. The total area of the seam volumes of both materials which were 
produced by a Yb:YAG laser has higher values (H340LAD: $1.9 \mathrm{~mm}^{2}$; TRIP700: $1.7 \mathrm{~mm}^{2}$ ), but the area of the welding seam is smaller. The reason for this effect is the higher beam quality of the $\mathrm{Yb}$ :YAG laser, which resulted in a larger heat affected zone.

Model and calculation of the tensile strength for linear bead-on-plate welding seams. The seam volumes for the welding seam and the hardened area was calculated for both materials. Based on this, a mathematical model can be generating for the specimens with linear bead-on-plate welding seams, which can be used to calculate the tensile strength.

The specimen on which the tensile strength calculations are to take place must be virtually split into three areas, as shown in Fig. 22.
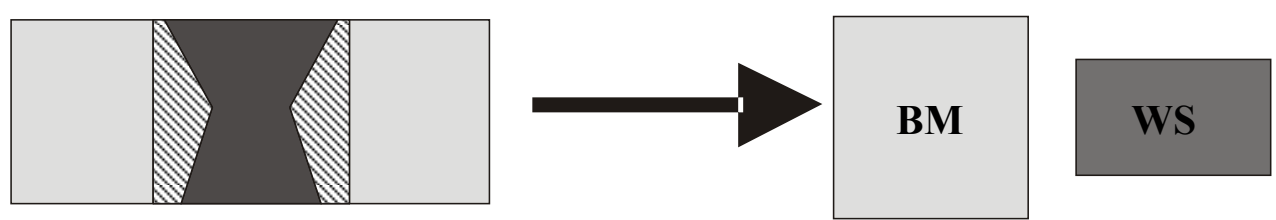

\section{2\%}

Fig. 22: Equivalent systems for the calculation of the tensile strength for linear bead-on-plate welding seams

One area represented the base material (BM) which is shown in light grey. Another area represents the welding seam (WS) which is marked dark grey. A third area represents the area for the heat affected zone (HAZ) and is displayed in striped.

The cross-sections of the virtual areas correspond to the proportions in the original specimen. The specimens are examined parallelly by a virtual machine. Torques and a skew tensile test can be neglected. Each specimen operates with their specific tension. Fig. 23 shows the analogous model.

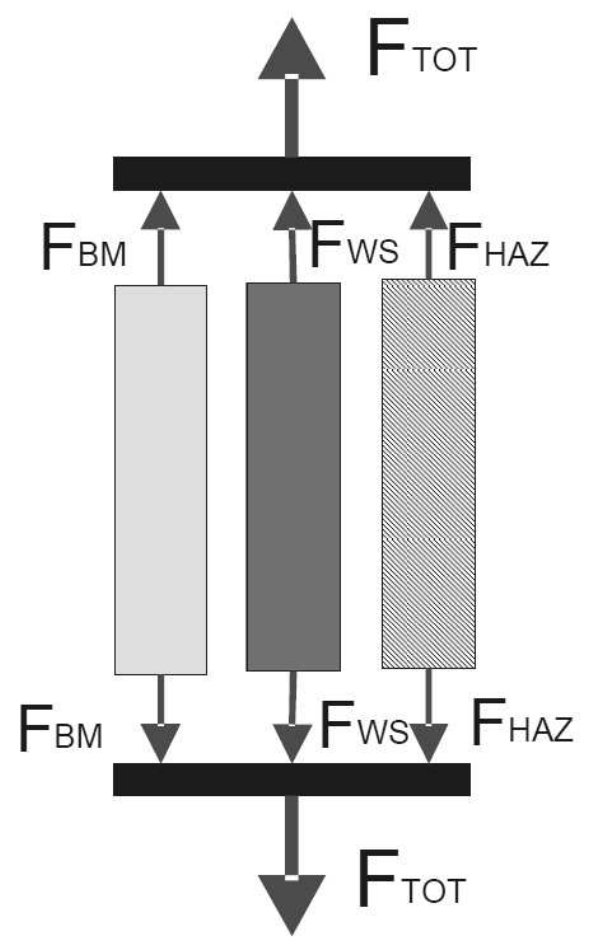

Fig. 23: Virtual tensile test for linear bead-on-plate welding seams

The tensile strength can be calculated with the mathematical formula 1 .

$R_{m}=\frac{R_{m_{\text {Seam }}} \times A_{\text {Seam }} \times n+R_{m H A Z} \times A_{H A Z} \times n+R_{m_{B M}} \times\left(A_{\text {Specimen }}-A_{\text {Seam }} \times n-A_{H A Z} \times n\right)}{A_{\text {Specimen }}}$ 
Following, the theoretical tensile strength of a specimen with three linear bead-on-plate welding seams of the material H340LAD is calculated. The measured hardness values can be determined by the tensile strength of the three areas.

In comparison to the conversion table between the hardness and the tensile strength follows with a hardness of $170 \mathrm{HV} 0.2$ a tensile strength of $545 \mathrm{~N} / \mathrm{mm}^{2}$. The hardness of the seam with $300 \mathrm{HV} 0.2$ corresponds to a tensile strength of $965 \mathrm{~N} / \mathrm{mm}^{2}$. The hardness in the heat affected zone to the base material hardness is decreases linear; the averaged hardness between the seam hardness and the hardness of the base material is used. For the average hardness of $235 \mathrm{HV} 0.2$ follows a theoretical tensile strength of $740 \mathrm{~N} / \mathrm{mm}^{2}$. The specimen surface is calculated by multiplying the specimen width and thickness. With a sheet metal thickness of $1.2 \mathrm{~mm}$ and a width of $20 \mathrm{~mm}$ an area of $24 \mathrm{~mm}^{2}$ was calculated. The seam surface with $1.148 \mathrm{~mm}^{2}$ was calculated at Table 3 . The size of the heat affected zone is $0.703 \mathrm{~mm}^{2}$. According to formula 1, for a sample with three linear bead-onplate welding seams, a tensile strength of $622.248 \mathrm{~N} / \mathrm{mm}^{2}$ was calculated. This value differs over $100 \mathrm{MPa}$ from the measured value.

If the theoretical tensile strength is not used, but the value of the base material, the measured tensile strength of $539 \mathrm{~N} / \mathrm{mm}^{2}$ can be calculated for the reference specimen. This value differs by only $14 \mathrm{MPa}$ to the real value of $525 \mathrm{MPa}$. For the specimen with two bead-on-plate welding seams, strength of $504 \mathrm{~N} / \mathrm{mm}^{2}$ was calculated. This value is $13 \mathrm{MPa}$ below the real measured value. For the specimen with one linear bead-on-plate welding seam, strength of $470 \mathrm{MPa}$ could be calculated. This value is $34 \mathrm{MPa}$ below the real tensile strength.

Fracture investigations. Fracture investigations were done, in order to analyse how failures at the material H340LAD and TRIP700 during the tensile test of the bead-on-plate welding seams resulted. In Fig. 24, the force flow at the beginning of the tensile test and during the tensile test are shown.
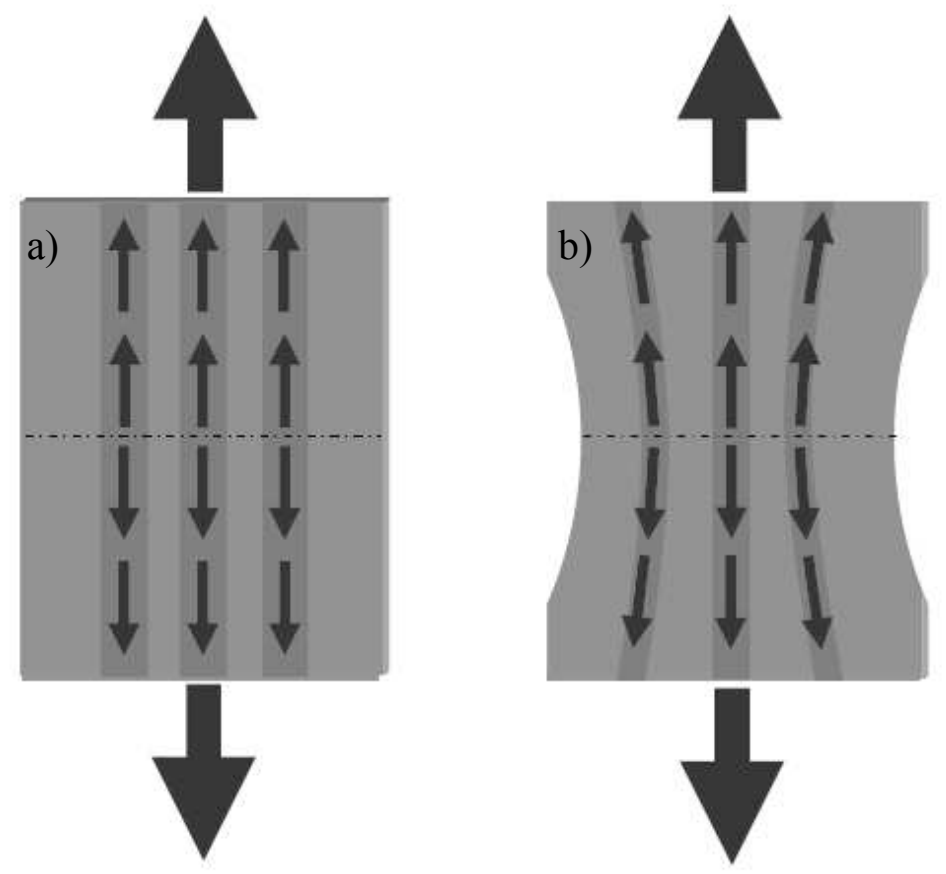

Fig. 24: Force flow a) without constrictions, and b) during the tensile test with constrictions 
At the beginning of the tensile test, the force flow of the specimen a) is linear and is parallel to the welding seams. The specimen exhibits no constrictions at the specimen border, and the welding seam consists of a martensite structures. During the tensile test, the constriction areas developed. As higher the elongation so higher the constriction area is developed. The constriction areas are equal to the border of the specimen. External bead-on-plate seams are depending of the constrictions and the force flow. It is adjusted to the direction of the bead-on-plate welding seams. At the end of the tensile test, crack initiation began at the external bead-on-plate welding seam. Fig. 25 shows the specimens H340LAD and TRIP700 with three linear bead-on-plate welding seams after the tensile test. Both specimens have different failure behaviours.

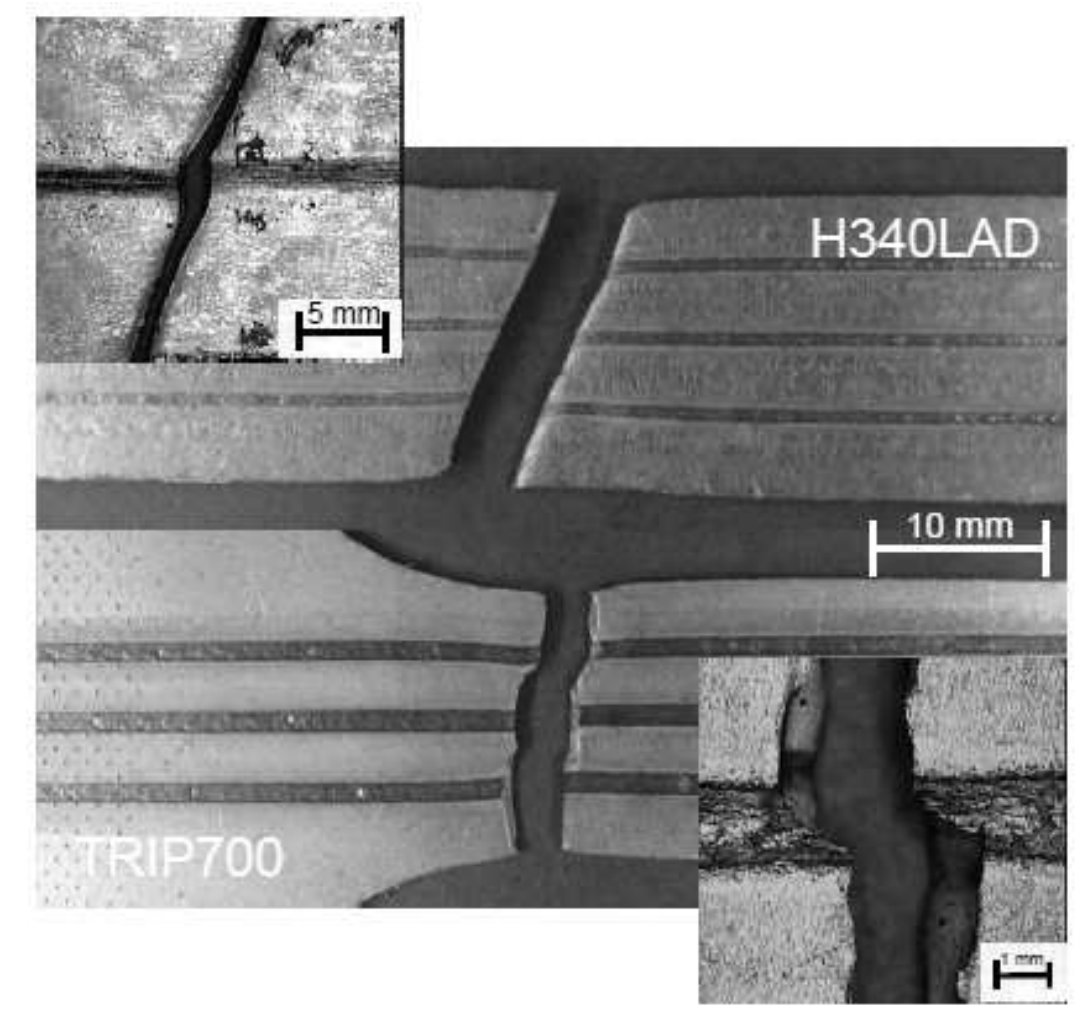

Fig. 25: Fracture after the tensile test of the specimen H340LAD and TRIP700 with three linear bead-on-plate welding seams

The specimen H340LAD with three linear welding seams which is shown in the upper part of the figure failed at the end of the tensile test with a ductile fracture. This effect is shown by the plane tip chamfer. Furthermore, it was shown that the seams at the tip chamfer are retreated and the specimen is highly constricted over the length. In comparison to this specimen, the specimen TRIP700 with three linear welding seams failed at the end of the tensile test with a brittle fracture. After the seam failed, the tip chamfer exhibited rough edges. In comparison to the material H340LAD the constrictions over the length are lower. Fig. 26 shows fracture behaviour of the various welding seam geometries. 

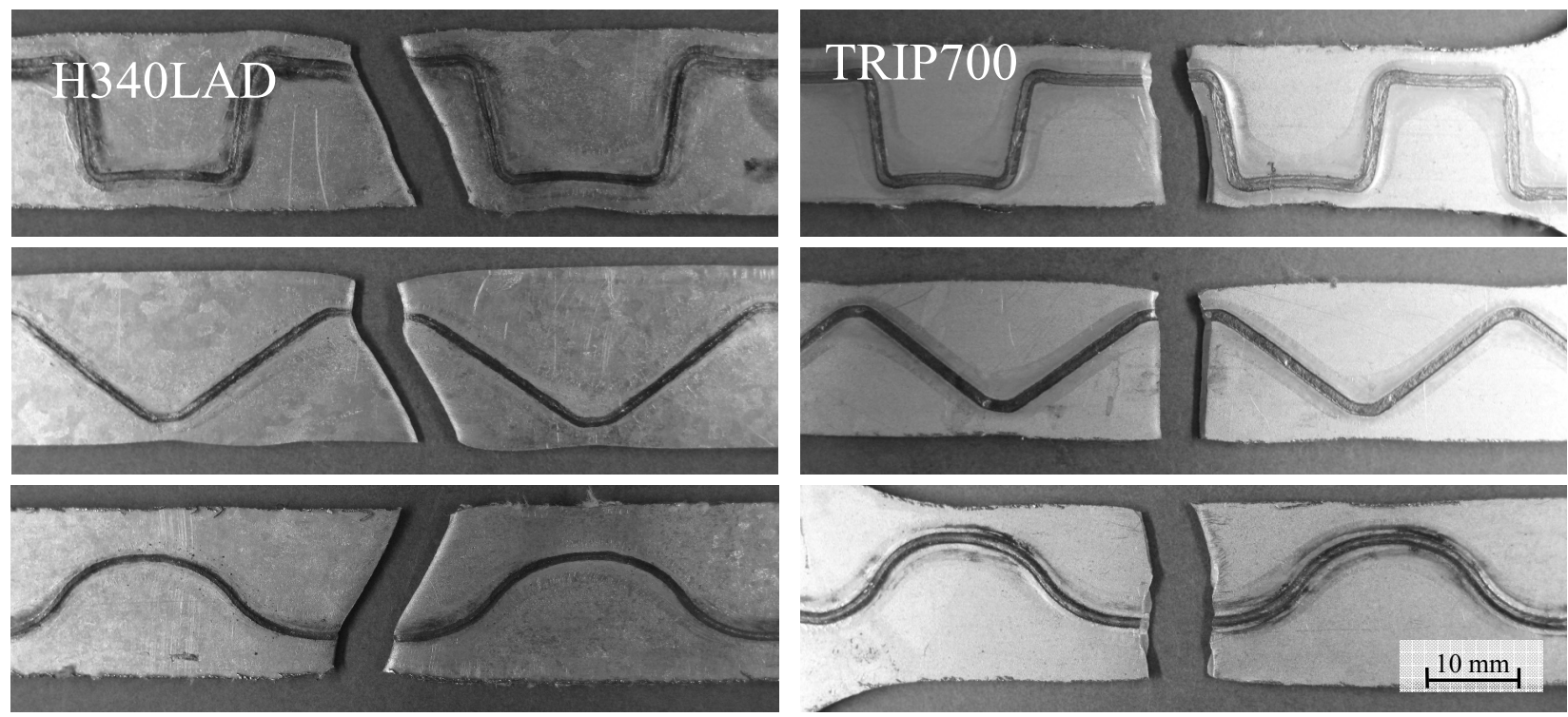

Fig. 26: Fractures of the specimens with various bead-on-plate welding seams

The identical effect of the fractures as at the linear welding seams was verified for the specimens with various bead-on-plate welding seams. In comparison to the linear bead-on-plate welding seams, the fracture area of the welding seam is near the specimen border. The constrictions appear at the border near the welding seam. The specimens of H340LAD with various bead-on-plate welding seams failed with a ductile fracture. In comparison to these specimens, the specimens of TRIP700 with various bead-on-plate welding seams failed with a brittle fracture.

Influence of the number of linear bead-on-plate welding seams. The bending strength of the number of seams induces a proportional increase. Fig. 27 presents the increase of the bending strength as a function of the number of seams. Specimens with one linear bead-on-plate welding seam increase the bending strength by an average of $14.4 \%$. Two linear bead-on-plate welding seams increased the bending strength by $23.6 \%$. Three seams exhibited a bending strength increase of $31.13 \%$.

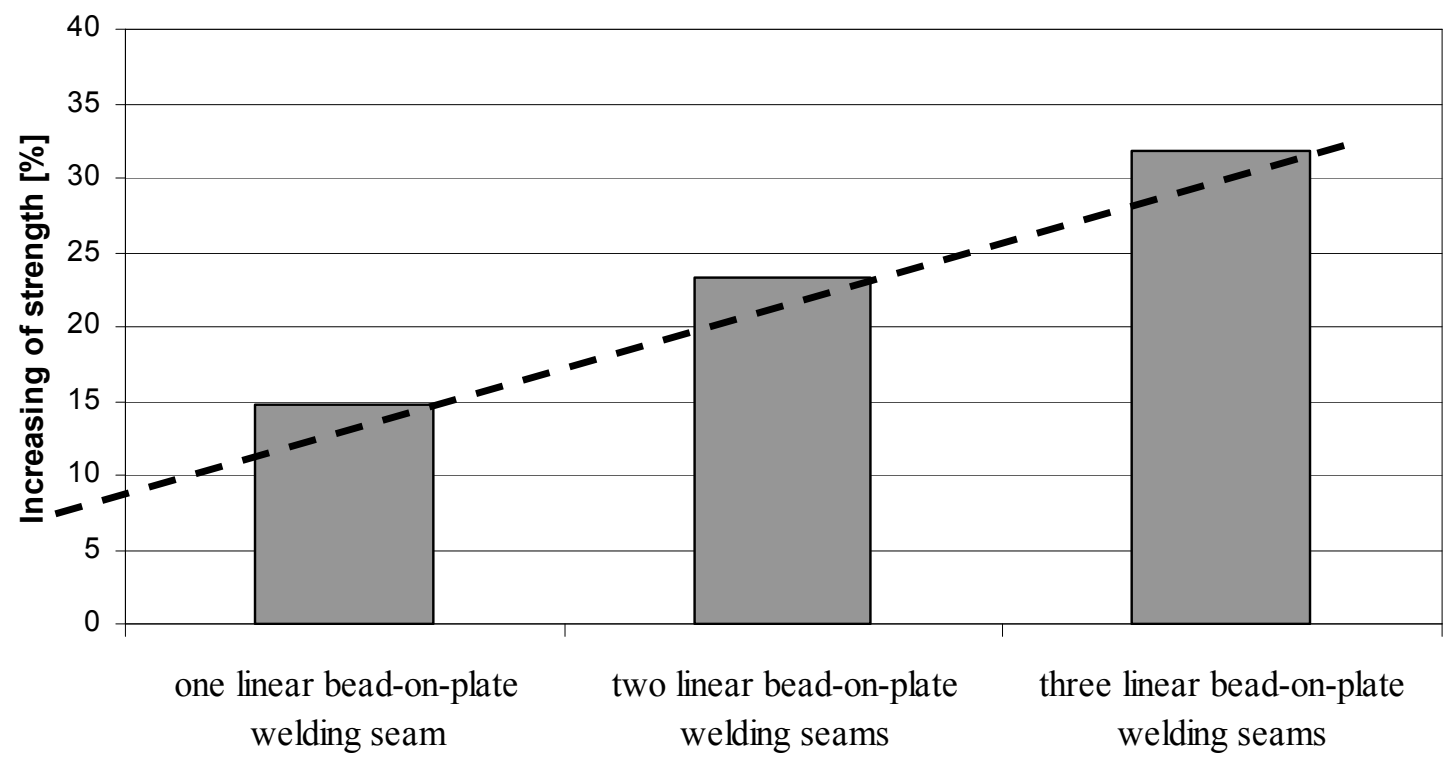

Fig. 27: Increasing of strength in reference to the number of linear seams 
The bending tests showed a proportional dependence between the maximum bending force and the number of linear seams. Similar to the tensile test, the proportion of hardened material, which has a higher bending moment than the base material, increased the bending force with every new welding seam.

Tensile tests of overlap welding seams (using an Nd:YAG laser). In Fig. 28, the stress-straincurve of H340LAD overlap welding seams is shown. The highest tensile stress of $475 \mathrm{MPa}$ and strain of $19.5 \%$ was measured for specimen C. Similar tensile strengths were obtained from the measurement of specimens B, D and E with $460 \mathrm{MPa}$. The elongation values of these three specimens are different. In the elastic region, the specimens showed the same gradient.

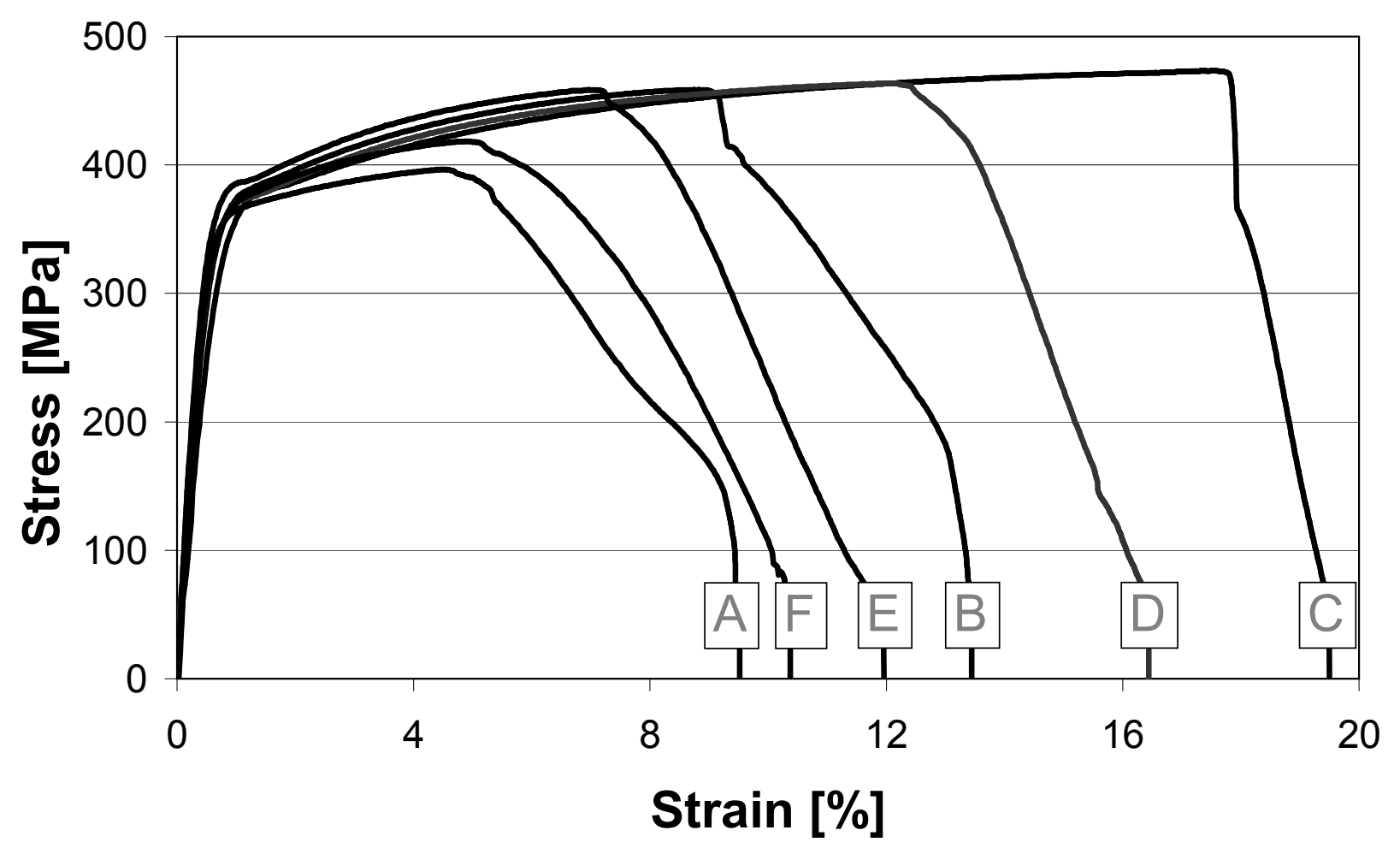

Fig. 28: Stress-Strain-Curves of H340LAD overlap specimens

In contrast to specimen $\mathrm{C}$, specimen A showed the lowest tensile strength of $397 \mathrm{MPa}$ and failure strain of $9.5 \%$. The same investigations were done with the material TRIP700. In Fig. 29, the stressstrain-curve of TRIP700 is shown. 


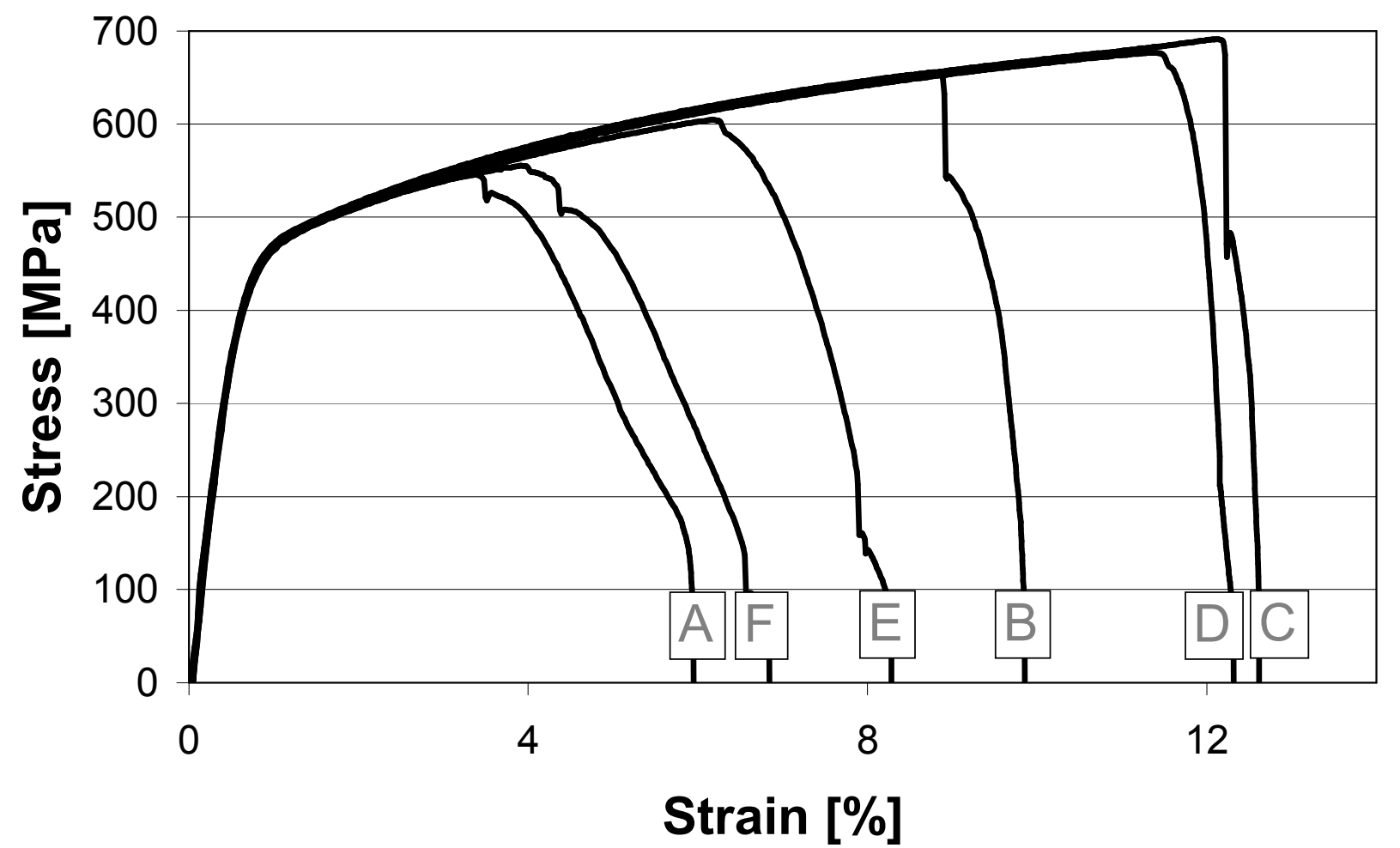

Fig. 29: Stress-Strain-Curves of TRIP700 overlap specimens

The TRIP700 overlap welding seams showed the same strength increasing effect as H340LAD. The highest strengthening effect was reached with specimen $\mathrm{C}$. In contrast to the bead-on-plate welding seams, elongation of the specimen $\mathrm{C}$ is the highest. On the one hand, the welding seam volume is higher, and on the other hand, the specimen did not crack in the welding seam, but in the base material. These are the reasons why the specimens show a high maximum strain. Specimen A, B, E and $F$ cracked within the overlap welding seam.

Bending tests. The mechanical bending properties were measured using a three point bending test. The three point bend test is a mechanical strength test, and presents properties such as the Young's modulus and the bending strength of a material. The tensile test is shown in Fig. 30.

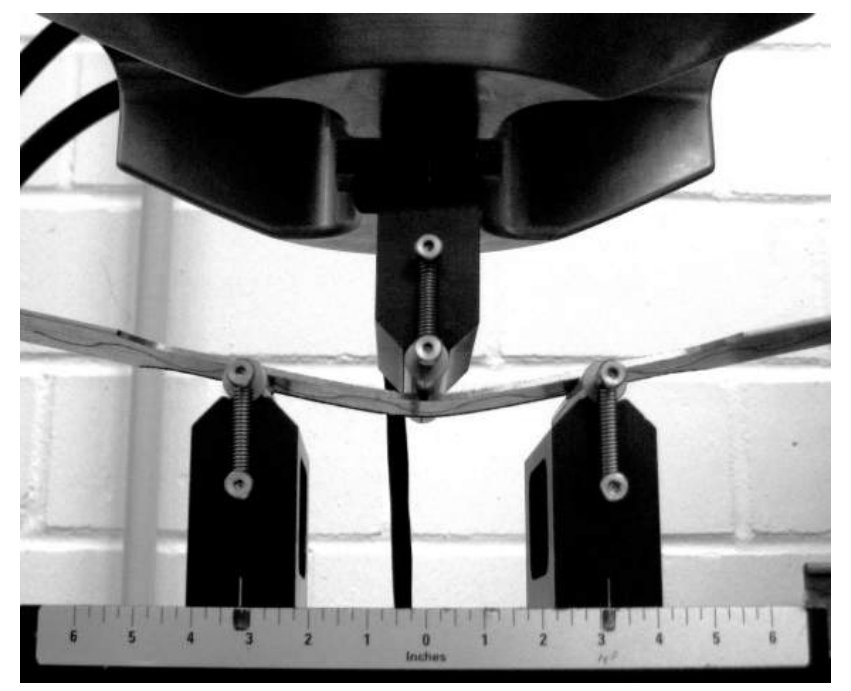

Fig. 30: Standardized bending tests - DIN EN 910 
The bending tests were carried out to demonstrate that bead-on-plate and overlap seams increase the rigidity of flat sheets. The same structures as used for the tensile tests were tested. Bead-on-plate welding seams were performed with a bending displacement of $10 \mathrm{~mm}$. The force which is needed to bend the sheets was measured. The geometries of the specimens were always identical. Both laser systems were used to produce the specimens. The length of the samples was $200 \mathrm{~mm}$, with a width of $20 \mathrm{~mm}$. The results of the 3-point bending test are presented in Table 4.

It is apparent that all specimens with welding seams need higher static forces than the specimens without welding seams. The maximum force needed to bend the sheet metal without welding seams is $136 \mathrm{~N}$ for H340LAD and $204 \mathrm{~N}$ for TRIP700. Specimens with welding seams need $50 \mathrm{~N}$ (Nd:YAG) and $19 \mathrm{~N}$ (Yb:YAG) higher force values to bend samples made of H340LAD, and $26 \mathrm{~N}$ (Nd:YAG) and $14 \mathrm{~N}$ (Yb:YAG) for samples made of TRIP700. These sheets require a force between $155 \mathrm{~N}$ and $268 \mathrm{~N}$ to displace them $10 \mathrm{~mm}$.

Further, a distinction between the force needed to bend the structures can be made. The structures D and E as well as the structure F exhibit identical force values. On the one hand, the structures $\mathrm{D}$ and $\mathrm{E}$ needed a maximum force of approximately $188 \mathrm{~N}$ (Nd:YAG) and 161 (Yb:YAG) for H340LAD, and $233 \mathrm{~N}(\mathrm{Nd}: Y A G)$ and $243 \mathrm{~N}(\mathrm{Yb}: Y A G)$ for TRIP700. On the other hand, a force of $217-219 \mathrm{~N}(169-177 \mathrm{~N})$ for H340LAD, and $248-268 \mathrm{~N}(244-277 \mathrm{~N})$ for TRIP700 was observed for the structures B and C. The reason for the difference is a result of the larger cross-sectional area of the welding seams. For structure $\mathrm{C}$, the sheets are strengthened by three welding seams. In contrast to specimen $\mathrm{G}$, there is an increase of $83 \mathrm{MPa}$ or $61 \%(\mathrm{Nd}$ :YAG), respectively. The bending procedure requires more force for this structure, due to the broader welding seam.

Table 4: Results of the three-point bending test with a distance of $80 \mathrm{~mm}$ between the lower bearings performed with bead-on-plate welding seams

\begin{tabular}{|c|c|c|c|c|c|c|c|c|}
\hline Specim. & $\begin{array}{c}\text { Laser } \\
\text { system }\end{array}$ & A & B & C & D & E & F & G \\
\hline $\begin{array}{c}\text { Max. } \\
\text { Force [kN] } \\
\text { H340LAD }\end{array}$ & Nd:YAG & 0.206 & 0.217 & 0.219 & 0.188 & 0.186 & 0.189 & 0.136 \\
\hline $\begin{array}{c}\text { Max. } \\
\text { Force [kN] } \\
\text { TRIP700 }\end{array}$ & Nd:YAG & 0.235 & 0.248 & 0.268 & 0.230 & 0.233 & 0.235 & 0.204 \\
\hline $\begin{array}{c}\text { Max. } \\
\text { Force [kN] } \\
\text { H340LAD }\end{array}$ & Yb:YAG & 0.167 & 0.169 & 0.177 & 0.161 & 0.155 & 0.161 & 0.136 \\
\hline $\begin{array}{c}\text { Max. } \\
\text { Force [kN] } \\
\text { TRIP700 }\end{array}$ & Yb:YAG & 0.218 & 0.244 & 0.277 & 0.237 & 0.243 & 0.233 & 0.204 \\
\hline
\end{tabular}

Overlap welding seams were subject to a bending displacement of $\mathrm{dB}=6.625 \mathrm{~mm}$. This bending displacement was calculated to achieve the same bending angle as the bending angle of the specimens with bead-on-plate welding seams. The angle calculated was $\alpha=152^{\circ}$. In Fig. 31 , the calculated bending angle is shown in a sketch. 


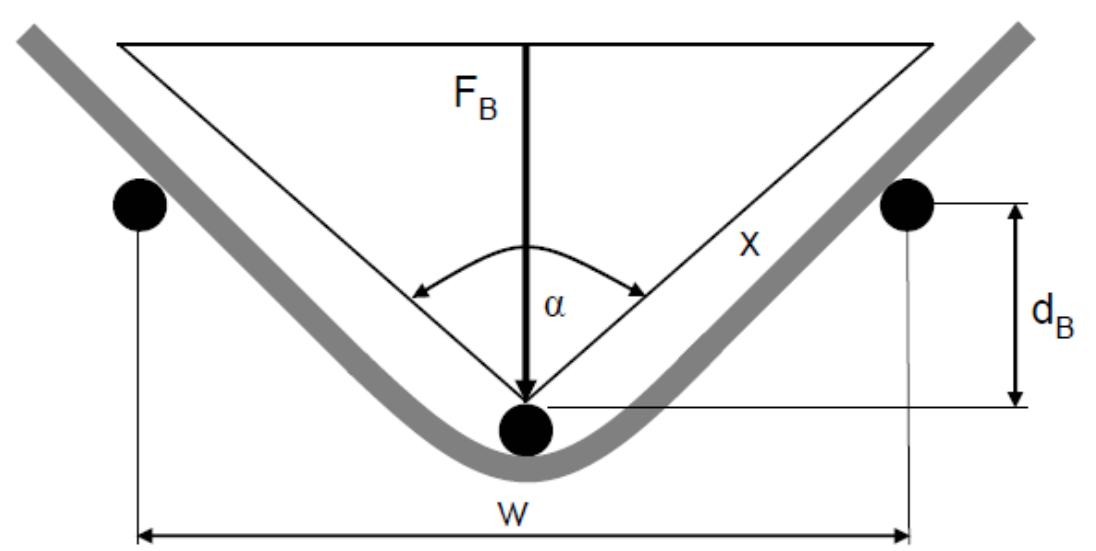

Fig. 31: Draft for calculating the different bending angle

The results of the three-point bending test are presented in Table 5.

Table 5: Results of the three-point bending test with a distance of $53 \mathrm{~mm}$ between the lower bearings performed with overlap welding seams

\begin{tabular}{|c|c|c|c|c|c|c|c|}
\hline Specim. & $\begin{array}{c}\text { Laser } \\
\text { system }\end{array}$ & A & B & C & D & E & F \\
\hline $\begin{array}{c}\text { Max. Force [kN] } \\
\text { H340LAD }\end{array}$ & $\begin{array}{c}\text { Nd:YA } \\
\text { G }\end{array}$ & 1.89 & 2.16 & 2.34 & 2.03 & 2.05 & 1.81 \\
\hline $\begin{array}{c}\text { Max. Force [kN] } \\
\text { TRIP700 }\end{array}$ & $\begin{array}{c}\text { Nd:YA } \\
\text { G }\end{array}$ & 2.85 & 3.29 & 3.71 & 3.03 & 3.20 & 2.89 \\
\hline $\begin{array}{c}\text { Max. Force }[\mathrm{kN}] \\
\text { H340LAD }\end{array}$ & $\begin{array}{c}\text { Yb:YA } \\
\text { G }\end{array}$ & 1.99 & 2.24 & 2.46 & 2.19 & 2.07 & 1.92 \\
\hline $\begin{array}{c}\text { Max. Force }[\mathrm{kN}] \\
\text { TRIP700 }\end{array}$ & $\begin{array}{c}\text { Yb:YA } \\
\mathrm{G}\end{array}$ & 2.63 & 3.12 & 3.49 & 2.91 & 2.84 & 2.74 \\
\hline
\end{tabular}

The bending test for specimen $\mathrm{C}$ requires the highest bending force of $2.34 \mathrm{kN}(\mathrm{Nd}: \mathrm{YAG})$ and 2.46 (Yb:YAG) to bend it $6.625 \mathrm{~mm}$ for H340LAD, and $3.71 \mathrm{kN}(\mathrm{Nd}: \mathrm{YAG})$ and 3.49 (Yb:YAG) for TRIP700. In contrast to the specimens with bead-on-plate welding seams, the overlap welding seams double the material thickness. This is a reason why the bending force is significantly higher. Especially a comparison between the specimen A, B and C shows the higher bending force needed. For both materials and laser systems, a higher force from specimen A to B of approximately $15 \%$ was needed. From specimen B to C, for bending $6.625 \mathrm{~mm}$, a higher force of $10 \%$ was necessary.

Calculation of the maximum force for bending linear overlap welding seams. Moreover, the welding volumes of the overlap welding seams were calculated, to develop a formula for the computation of the maximum force that is needed for the bending test. For the calculation of the maximum force that is needed for bending the specimens by $6.625 \mathrm{~mm}$, formula 2 can be used [11]:

$$
F_{B}=\frac{48 d_{B} E_{\text {substitute }} I_{\text {fusion }}}{w^{3}}
$$

$\mathrm{I}=$ geometrical moment of inertia, $\mathrm{d}_{\mathrm{B}}=$ bending length, $\mathrm{w}=$ distance between the bending stamps 
Formula 1 is repositioned to formula 3 like:

$$
E_{\text {substitute }}=\frac{F_{B} w^{3}}{48 d_{B} I_{\text {fusion }}}
$$

For the derivation of Young's modulus of elasticity the maximum force that is needed for the bending test of specimen A of TRIP700 is used, which is about $F_{B}=2850.98 \mathrm{~N}$.

$\mathrm{F}_{\mathrm{B}}$ must be implant in formula 2 thus the Young's modulus of elasticity is about $\mathrm{E}_{\text {substitute }}=25743 \mathrm{~N} / \mathrm{mm}^{2}$.

Therefore, the Young's modulus of elasticity has to be developed with the material properties and the volume of the welding seam.

Consequently the new formula for the modulus of elasticity is designed like:

$$
E_{\text {substitute }}=R_{P 0,2 \%} \cdot K_{1} \cdot K_{2}^{\left(\frac{\text { weldingvolume 2-weldingvolume } 1}{\text { weldingvolume } 1}\right)}
$$

with $\mathrm{K}_{1}=64.357$ and $\mathrm{K}_{2}=1.1547$ for the material TRIP700 whereas $\mathrm{K}_{2}$ is approximating zero for calculating specimen A.

The development of a formula for the material H340LAD is similar. In this connection, the coefficients are about $\mathrm{K}_{1}=50.324$ and $\mathrm{K}_{2}=1.1372$.

Finally, the respective formula 3 has to be implanted in formula 1 for calculating the maximum force. In Table 6 , the maximum bending forces of the calculation are presented.

Table 6: Calculated maximum bending forces

\begin{tabular}{|c|c|c|c|}
\hline Specim. & A & B & C \\
\hline Max. Force $[\mathrm{kN}]$ H340LAD & 1.89 & 2.15 & 2.45 \\
\hline Max. Force [kN] TRIP700 & 2.85 & 3.29 & 3.80 \\
\hline
\end{tabular}

The result of the practical attempts in contrast to the theoretical calculations shows a percentage difference of the bending force of $4.7 \%$.

Tensile tests of the combination of overlap and bead-on-plate welding seams. After the research on the bead-on-plate welding seams and the overlap welding seams tests, a combination of both was done. The results of the combination of bead-on-plate and overlap welding seams are shown in Table 7. 
Table 7: Results of the tensile test with the combination of overlap and bead-on-plate welding seams

\begin{tabular}{|c|c|c|c|c|}
\hline \multirow{2}{*}{ Specimen } & Material & $\begin{array}{c}\text { Stress } \\
{[\mathrm{MPa}]}\end{array}$ & Strain [\%] & $\begin{array}{c}\text { Contrast to overlap } \\
\text { specimens (Nd:YAG) }\end{array}$ \\
\hline \multirow{2}{*}{} & H340LAD & 382.17 & -9.15 & $-18.19 \mathrm{MPa}(4.51 \%)$ \\
\cline { 2 - 5 } & TRIP700 & 514.53 & -5.11 & $-31.09 \mathrm{MPa}(6,04 \%)$ \\
\cline { 2 - 5 } & H340LAD & 459.55 & -13.18 & $-14.37 \mathrm{MPa}(3.12 \%)$ \\
\hline \multirow{2}{*}{ TRIP700 } & 656.68 & -4.40 & $-34.52 \mathrm{MPa}(6.16 \%)$ \\
\hline & TRIPLAD & 412.29 & 7.51 & $11.93 \mathrm{MPa}(3.04 \%)$ \\
\hline & H340LAD & 494.80 & 11.21 & $20.88 \mathrm{MPa}(4.22 \%)$ \\
\cline { 2 - 5 } & TRIP700 & 694.58 & 4.68 & $3.38 \mathrm{MPa}(0,48 \%)$ \\
\hline
\end{tabular}

Specimens with a combination of bead-on-plate and overlap weldings seams produced with an $\mathrm{Nd}$ :YAG laser were investigated. The welding geometries for testing were linear parallel bead-onplate welding seams in combination with one or three overlap welding seams. Furthermore, specimens with four wave bead-on-plate welding seams in combination of one or three overlap welding seams were investigated, too. It becomes clear that the difference of the stress to the overlap welding seams is lower than $7 \%$. This shows that the bead-on-plate welding seams did not increase rigidity. The difference between the specimens with three parallel and wave bead-on-plate welding seams is peculiar. In contrast to the specimens with overlap welding seams, the specimens with three parallel bead-on-plate and overlap welding seams decreased the stress. The specimens with wave bead-on-plate welding seams in combination with linear overlap welding seams show an increasing of rigidity.

Simulation of the tensile and bending test for the verification. The finite element method (FEM) was used to simulate the tensile and bending tests, and to predict the stress distribution in the specimen. For the simulation, the program "SYSWELD" was used. The simulation of the tensile and bending tests showed the possibility to simulate these kinds of investigations using the finite element method. A fine meshed model for the simulation was selected. This caused a high calculating time for the tensile test results. Most boundary conditions for the calculation were included. In Fig. 32, a model specimen with one linear bead-on-plate welding seam is shown. 


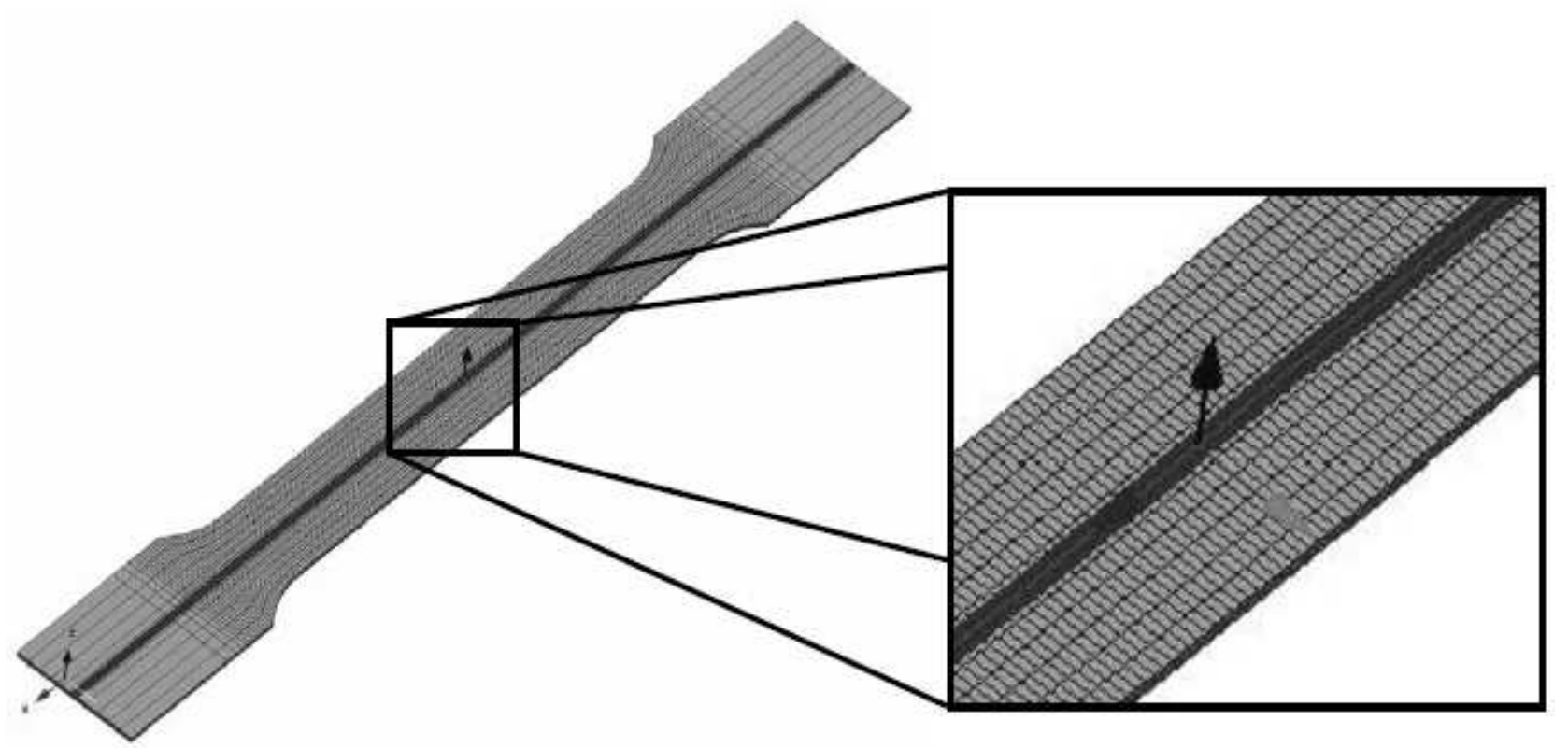

Fig. 32: Model specimen with one linear bead-on-plate welding seam for simulation

After the simulation, the deformed specimen is present. The values for the stress-strain curve can be extracted from the results. Simulations were done for both materials H340LAD and TRIP700. A welding seam width of $1 \mathrm{~mm}$ was defined. The results of the tensile stress simulation are shown in Fig. 33. In comparison to the practical tensile test, the elastic area of the simulated tensile test proceeded with a sharp increase. After this, the malleable area of all investigations was approximated over the length. The test was done over a strain of $10 \%$.

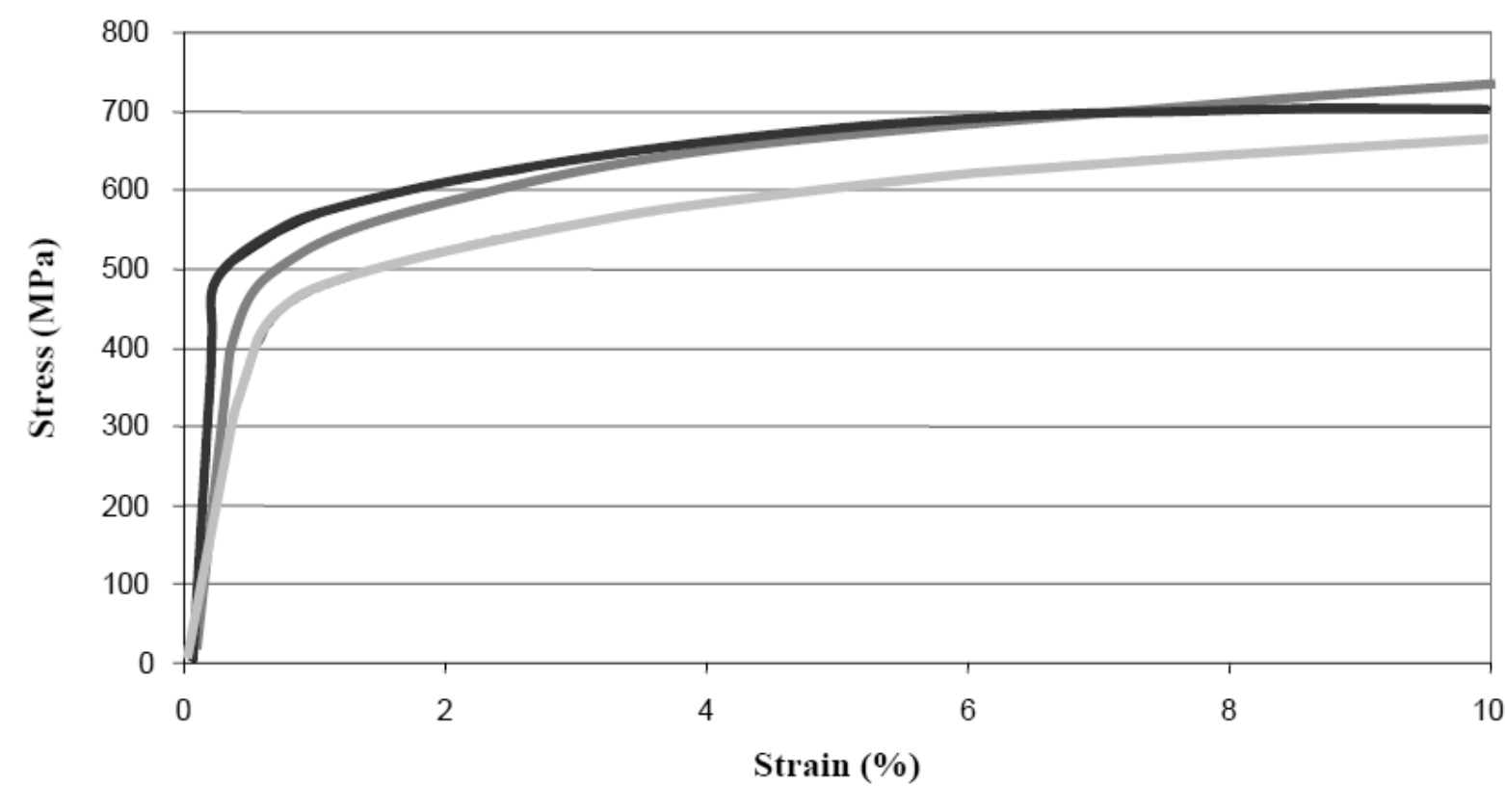

Fig. 33: Results of simulated and practical tensile tests

The differences between the simulation and the practical test exhibited of the not homogenous weld pool dimension, the isotropy of the material and of the seam imperfections. A tolerance of the verification of $8.7 \%$ between the practical and simulated test was calculated. 


\section{Summery}

The investigations show that mechanical characteristics can be produced by using local physical and geometrical effects. It has been demonstrated that different geometrical welding seams on metal sheets can increase the strength and the rigidity. For the investigations, a micro-alloyed steel H340LAD and a residual austenite steel TRIP700 were used. These kinds of steels are used for structural parts in the automotive industry, for safety-relevant elements. Welding seams were produced using an Nd:YAG and $\mathrm{Yb}: \mathrm{YAG}$ laser, and tested in tensile tests as well as in three-point bending and fatigue tests. Furthermore, metallographic analyses, residual stress tests, deformation measurements, fracture investigations and calculations for the maximum bending force and tensile stress of linear welding seams were carried out. The simulations of the tensile test of the specimens were done. Six different welding seam geometries for bead-on-plate, and overlap welding seams and the combination of both were investigated. Three specimens exhibited straight, linear seams and three other specimens exhibited various welding seams. One more specimen without welding seams was tested as a reference.

The result of the metallographic tests showed that the welding seams exhibited martensitic structures with a hardness increasing up to 170 HV0.2 for H340LAD, and 245 HV0.2 for TRIP700. The tensile strength measured showed that more stress was needed to rupture the specimens with welding seams than for the specimens without a welding seam. The reason for this effect is the heat influence of the laser beam, causing the base structure of the high strength steels to change to coarse-grained martensitic structures.

On one bead-on-plate specimen, three parallel, long welding seams were made. In contrast to the specimen without welding seams, $30 \%$ more stress was needed to obtain a rupture. Due to the increased tensile strength of the specimen, strain was reduced by $40 \%$. The same effect was observed as for the overlap welding seams. Only a small influence was observed between using an $\mathrm{Nd}: Y A G$ and a $\mathrm{Yb}: \mathrm{YAG}$ laser for the producing process and increasing strength and rigidity. A difference of the seam volume calculations was observed. The Yb:YAG laser exhibit a higher beam quality, and this is a reason for a smaller weld pool and an expanded heat affected zone.

The result of the residual stress test is that the specimen without bead-on-plate welding seams exhibited compressive stress before the fatigue investigation was started. After the procedure, the specimen exhibited tensile stress. In comparison to this specimen, one specimen with one linear bead-on-plate welding seam was tested. Before the fatigue test was started, the specimen at the area with the welding seams tensile stress had tensile stress. All other areas exhibited compressive stress. After the investigation, a higher compressive stress was measured on the left side of the welding seam, and the right side exhibited tensile stress.

The deformation measurement results showed an explicit dependency of the deformation with small strain of the seam geometry. Fracture investigations show ductile fractures for the material H340LAD, and brittle fractures for TRIP700. All specimens with various bead-on-plate welding seams failed in the seam near the specimen border.

The three-point bending test was carried out. The same strengthening effect as observed in the tensile tests resulted. The highest force of $219 \mathrm{~N}$ for the bead-on-plate welding seams for H340LAD, and $3.71 \mathrm{kN}$ for the overlap welding seams for TRIP700 was needed for bending the specimen with parallel welding seams. A reason for the higher necessary force is the larger welding seam surface with martensitic structures available at the bending stamp was determined. The lowest bending force value of $136 \mathrm{~N}$ for H340LAD was measured for the specimen without the welding seams. A formula was developed for calculation of the maximum bending force of overlap linear welding seams.

Furthermore, the heat treatment leads to higher fatigue strength for the material H340LAZE. The higher the volume that is heat treated in the area of interest, the more the fatigue strength increases, if the type of weld and the stress are identical. If the weld is orientated perpendicularly to the direction of force, it decreases the fatigue strength.

Mechanical investigations were simulated by using the FEM simulation. With fine meshed models it is possible to simulate the process and tensile test. A tolerance of the verification between 
the practical and simulated tests of $8.7 \%$ was calculated. Furthermore, a formula for calculating the tensile strength for linear bead-on-plate welding seams was developed. For these kinds of specimens, a maximum divergence of $9.1 \%$ was calculated.

\section{Outlook}

The investigations show that it is possible to increase the rigidity and the strength of flat sheet metal with simple geometries of bead-on-plate and overlap welding seams.

In the future, it will be necessary to compare the results with other high strength steels to obtain more information about the material properties after the welding process. More investigations can be done with other geometrical welding seams, and the combination of bead-on-plate and overlap welding seams.

In order to be able to analyse the complex stress states in the range of multidimensional welding seams, further fatigue tests will be needed. More investigations should show the results of forceloaded, 3-D specimens, for example the structure strength of passenger cabins. To analyse the complex stress states in the range of multidimensional welding seams, further fatigue tests will be needed.

\section{Acknowledgments}

This work is founded by the "German Research Foundation (DFG)" (SFB 675, TP B1). The authors would like to thank the DFG for their support.

\section{References}

[1] N.N., ULSAB-AVC Body Structure Materials, Technical Transfer Dispatch 6, ULSAB-AVC Consortium, Mai 2001

[2] H. Haferkamp, J. Bunte, P. Cordini, A. Borman, B. Block: Laser welding of steel rail coaches. In: 3rd International Institute of Welding Congress. 1.-3. Dezember, Tehran, Iran. (2003). pp. $70-78$

[3] H. Haferkamp, A. Ostendorf, J. Bunte, P. Cordini, A. Bormann, B. Block: Laser welding of steel rail coaches. In: Proceedings of the Int. Conference on Manufacturing Engineering; Halkidiki, Greece; 3.-4. October 2002. pp. 711-719

[4] W. Rath: Remote Laser Welding System Using Slab Laser Technology: Process Data and Technical Applications. Proceeding of the $10^{\text {th }}$ Annual Automotive Laser Applications Workshop, March 12-13, 2002, MI, USA, pp. 119-127

[5] W. Becker, M. Beck, R. Bernhardt: Potential of robot-guided remote laser welding. Proceedings of Laser Assisted Net Shape Engineering LANE 4, Erlangen, (2004), pp. 201-210

[6] E.G. Opbroek, et al.: Advanced High Strength Steel (AHSS) Application Guidelines. International Iron \& Steel Institute, March 2005

[7] Sysweld 2002.1, Reference Manual, ESI Group, Aachen, (2002)

[8] M. Hück: An improved method for the analysis of staircase test. Materials Technology and Testing 12/83, Vol. 14, No. 12, December 1983, Verlag Chemie

[9] J. Liu: Fatigue strength calculation of metallic structure. Papierflieger, Clausthal-Zellerfeld, (2001)

[10]M. Schimek, O. Meier, A. Ostendorf, H. Haferkamp: Local strength and rigidity increase of sheet metal using bead-on-plate laser welds. In: 26th International Congress on Applications of Lasers \&Electro-Optics ICALEO, 29.10.-01.11. 2007, Orlando, Florida

[11]T. Hicks: Mechanical Engineering Formulas Pocket Guide. McGraw-Hill Professional; 1 edition, (2003) 